\title{
Balloon expandable coronary stent materials: a systematic review focused on clinical success
}

\author{
Jithin Vishnu ${ }^{1} \cdot$ Geetha Manivasagam ${ }^{1}$ (1) Diego Mantovani ${ }^{2} \cdot$ Anjaneyulu Udduttula $^{3,4} \cdot$ Melanie J. Coathup $^{5}$. \\ Ketul C. Popat ${ }^{6} \cdot$ Pei-Gen Ren ${ }^{3} \cdot$ K. G. Prashanth ${ }^{1,7}$
}

Received: 5 October 2021 / Revised: 11 January 2022 / Accepted: 13 January 2022 / Published online: 31 January 2022

(c) The Author(s), under exclusive licence to Springer Nature Switzerland AG 2022, corrected publication 2022

\begin{abstract}
Balloon expandable coronary stenting has revolutionized the field of interventional cardiology as a potential, minimally invasive modality for treating coronary artery disease. Even though stenting is successful compared to angioplasty (that leaves no stent in place), still there are many associated clinical complications. Bare metal stents are associated with in-stent restenosis caused mostly by neointimal hyperplasia, whereas success of drug-eluting stents comes at the expense of late-stent thrombosis and neoatherosclerosis. Even though innovative and promising, clinical trials with bioabsorbable stents reported thrombosis and a rapid pace of degradation without performing scaffolding action in several instances. It should be noted that a vast majority of these stents are based on a metallic platform which still holds the potential to mitigate major cardiovascular events and reduced economic burden to patients, alongside continuous improvement in stent technology and antiplatelet regimes. Hence, a systematic review was conducted following PRISMA guidelines to assess the clinically relevant material properties for a metallic stent material. From a materials perspective, the major causes identified for clinical failure of stents are inferior mechanical properties and blood-material interaction-related complications at the stent surface. In addition to these, the stent material should possess increased radiopacity for improved visibility and lower magnetic susceptibility values for artefact reduction. Moreover, the review provides an overview of future scope of percutaneous coronary interventional strategy. Most importantly, this review highlights the need for an interdisciplinary approach by clinicians, biomaterial scientists, and interventional cardiologists to collaborate in mitigating the impediments associated with cardiovascular stents for alleviating sufferings of millions of people worldwide.
\end{abstract}

Keywords Coronary artery disease $\cdot$ Thrombosis $\cdot$ In-stent restenosis, Bare metal stents $\cdot$ Bioabsorbable stents · Radiopacity $\cdot$ Magnetic susceptibility

\section{Introduction}

Cardiovascular disease (CVD), associated with illness related to heart or blood vessels, is the leading cause of mortality all over the world, accounting for 17.9 million deaths, according to World Health Organization's annual compilation of health statistics carried out in 2016 [1,2]. Coronary artery disease (coronary arteriosclerosis or coronary atherosclerosis or ischemic heart disease) is the most common type of CVD in which the interior walls of coronary arteries

Jithin Vishnu

jithinvshnu@gmail.com

Geetha Manivasagam geethamanivasagam@vit.ac.in

Extended author information available on the last page of the article (which supply blood to heart muscles) become thickened and narrowed (stenosis) by the proliferation of atherosclerotic plaques, mainly composed of fatty acid and fibrous compounds. Consequently, blood flow supplying metabolites and oxygen to cardiac muscle is reduced, thus leading to fatal medical conditions such as angina (severe heart pain), myocardial infarction (heart attack), and even stroke.

Historically, apart from pharmaceutical treatment and severely changing the lifestyle, the first developed clinical solution for treating coronary artery disease was "balloon angioplasty". A flexible polyvinyl chloride balloon was first reported by Andreas Gruentzig in 1977, which revolutionized the medical field in the twentieth century [3]. Angioplasty is performed by inflating the balloon at the blocked region thereby compressing the plaque against the arterial wall, widening the vessel and restoring blood flow, then 
deflating the balloon and removing the catheter on which the balloon is mounted. Initially, this clinical procedure was associated with catastrophic complications such as abrupt vessel closure and restenosis [4]. These complications were rectified by the introduction of the coronary stent, a mechanical support for the narrowed section of the arteries after angioplasty. It was first experimented in humans by Puel and Sigwart in 1986 [5]. A stent is a mesh-like tubular structure which is used to mechanically support the redilated clogged artery by a minimally invasive procedure. The stent in the crimped state is placed over the balloon-tipped catheter and is guided to the occluded region. As the balloon is inflated, the crimped stent is expanded thereby compressing against the arterial lumen and during balloon deflation, the stent remains as a scaffold to keep the lumen open.

The stenting procedure and the pertinent materials applicable for the three generations of balloon expandable coronary stents are depicted in Fig. 1. Bare metal stents (BMS) are appropriate candidates for the manufacturing of stent tubes as metals have high radial strength, enhanced corrosion resistance, and biocompatible properties. Coronary stent materials for BMS include stainless steel (316L SS) and cobalt-chromium alloys (which are the most widely used clinical balloon expandable stent materials), and other alloys of platinum, tantalum, and niobium. Nickel-titanium alloy (nitinol) represents another dominant class of stents termed as self-expandable stents which rely on shape memory/superelastic property [6]. The advent of drug-eluting stents (DES) was the second notable milestone, which use a drug-loaded polymer coated over a metallic platform for localized anti-proliferative, anti-inflammatory, and immunosuppressive drug delivery $[7,8]$. The most novel and recent approach of cardiovascular stent design is the third generation of bioabsorbable stents (BAS), made from magnesium alloys, iron and its alloys, and most recently zinc alloys to provide transient support to arterial walls $[9,10]$. In addition to these metals, a variety of bio-absorbable polymers such as poly (L-lactic acid) (PLLA), poly (DL-lactic acid) (PDLA), poly-epsilon-caprolactone (PCL), and poly (glycolic acid) (PGA) have been utilized for BAS applications [11].

Despite all these developments, an ideal stent material with improved ischemic outcomes with no revascularization procedures and with reduced incidence of thrombotic events is yet to be developed. BMS are associated with in-stent restenosis (ISR) caused mostly by neointimal hyperplasia and the success of DES comes at the expense of late-stent thrombosis (LST), late-stent malapposition, and neoatherosclerosis $[12,13]$. Stent strut thickness is a predominant factor dictating the occurrence of restenosis. The extent of ISR is primarily related to the extent of damage occurring at the
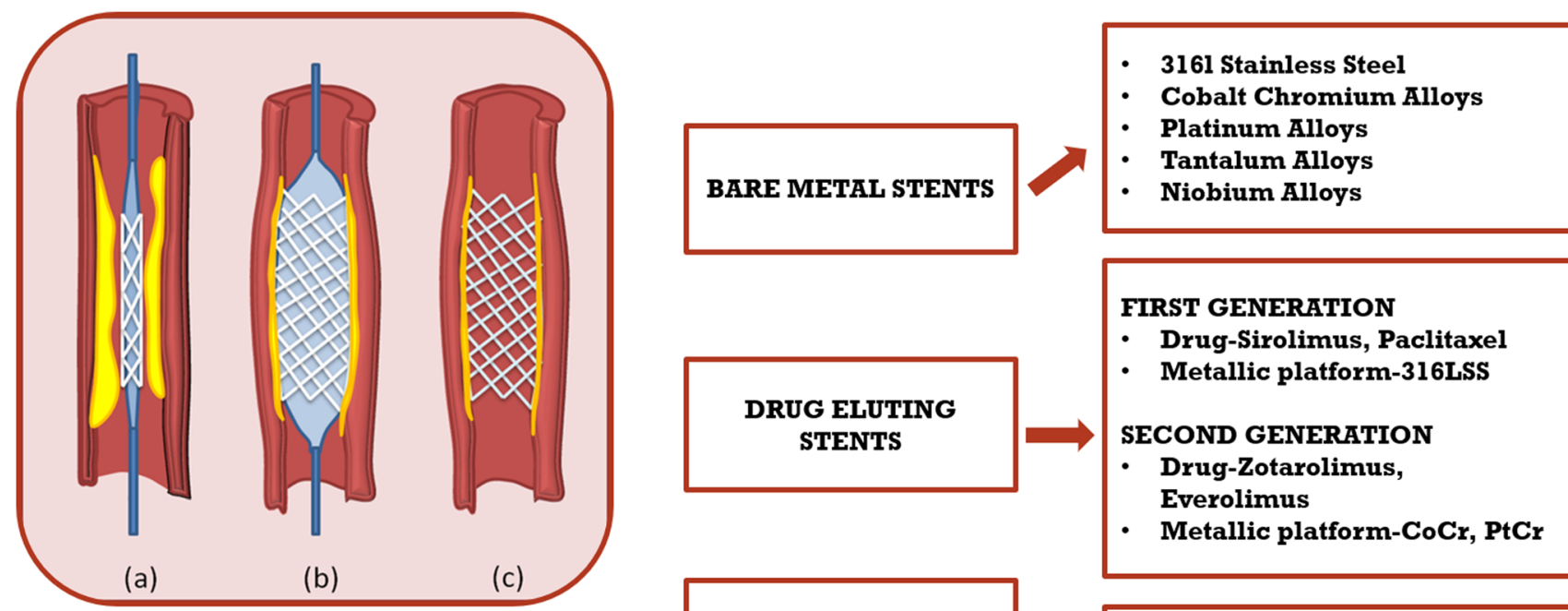

(a) Stent in the crimped state guided to region of blood clot inside artery via catheter wire

(b) Stent expansion via balloon inflation

(c) Balloon tipped catheter removed and expanded stent restores normal blood flow

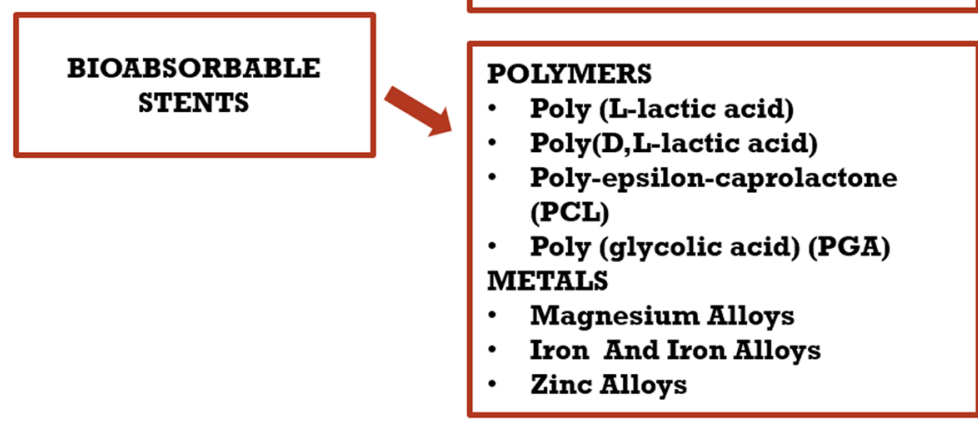

Fig. 1 Clinically used materials for balloon expandable coronary stents 
time of implantation. An implanted stent with an increased strut thickness can induce arterial wall injury as these struts of stents can induce local deep trauma and generate chronic stretch [14]. A stent material possessing a higher radial stiffness can prevent arterial recoil and restenosis rate. Such elastic recoil of the arterial wall can lead to restenosis, often associated with the constriction of the artery owing to the development of a fibrous scar tissue (termed as negative remodelling) and the persistence of the plaque [15]. Even though innovative and promising, clinical trials with BAS reported thrombosis and a rapid pace of degradation without performing scaffolding action in several instances [16]. It is noteworthy that an overwhelming majority of these stent platforms are based on a metallic platform whether it is BMS, DES, or BAS. Metallic materials hold the potential for innovative stent applications in terms of mitigating major cardiovascular events and reduced economic burden to patients with the continuous improvement in stent technology and antiplatelet regimen $[17,18]$. Increased financial consequences associated with stents demand prospective technology assessment and innovations in healthcare which can be attained by understanding the requirements for materials for such devices. A pertinent understanding of desirable properties for an ideal metallic stent is essential for the biomaterials and medical research community to bring the materials and technology to fruition. Most of the recent reviews are based on DES [19, 20] and BAS [11, 21, 22]. However, an updated and focused review encompassing the stent material, stent surface, and clinical and interventional aspects of stent technology is missing in literature. In view of all these perspectives, the primary motive of this systematic review is to reduce the knowledge barrier between clinicians, biomaterial scientists, engineers, and interventional cardiologists, so as to provide a framework to work together for developing a propitious stent material.

\section{Methodology}

Data from various electronic databases such as Web of Science, PubMed, ScienceDirect, and GoogleScholar were collected in accordance with PRISMA (Preferred Reporting Items for Systematic Reviews and Meta-Analyses) recommendations for systematic review which will help in maintaining transparency and assist future research [23, 24]. The search strategy used is shown in Fig. 2.

\section{Research question}

The initial step of this systematic review was the formulation of a research question: "Which are the major complications associated with cardiovascular stent materials?".

\section{Information sources}

Electronic databases Web of Science, PubMed, ScienceDirect, and GoogleScholar were used in the second step to systematically search the relevant data. An electronic search was conducted with following keywords: 'Coronary stent materials properties', 'Balloon expandable stents desirable properties'. Additional keywords specified were clinical success, enhanced interventional procedure, reduced thrombosis and restenosis, and surface modification of stents. Following the search using the abovementioned keywords, duplicates were picked and ruled out from the list of articles. The references of the consulted papers were also scanned for any pertinent information.

\section{Inclusion and exclusion criteria}

Further refinement of the search was carried out by including only full-text articles primarily focused with the aim of this review. As this research work is completely focused on balloon expandable-type stents, the works related to other class of self-expanding stents were excluded. Furthermore, data dealing with tracheal stents, prostatic stents, esophageal stent, and ureteral stents were excluded. Papers authored in the English language were only included for this review.

\section{Results}

Figure 2 summarizes the results based on the systematic review and a total number of 127 articles were selected for the detailed review. Following the systematic analysis, major determining properties for successful clinical application of coronary stents are found to be mechanical properties, hemocompatibility, radiopacity, and magnetic susceptibility as illustrated schematically in Fig. 3.

In spite of all the clinical developments, the mechanical properties of stent metallic platforms are unable to adapt to the surrounding biological environment leading to adverse clinical complications such as ISR, stent thrombosis, and subsequent target lesion revascularization $[25,26]$. In a clinical study, involving 6555 patients with 16,482 DES, stent fracture was found to be more frequently observed after DES implantation and almost one-fourth of fractured stents were subjected to target lesion revascularization [27]. Similarly, Chhatriwalla et al. reported 95\% of stent fracture cases and another famous clinical trial, the Nordic Intravascular Ultrasound Study, revealed 24\% of stent fracture occurrence among the implanted BMS [28, 29]. The ensuing clinical implications regarding these stent fractures are still enigmatic. In this respect, the fracture of stent material due to periodic mechanical loading by tortuous blood vessel walls is a serious concern. Hence, identifying the relationships 


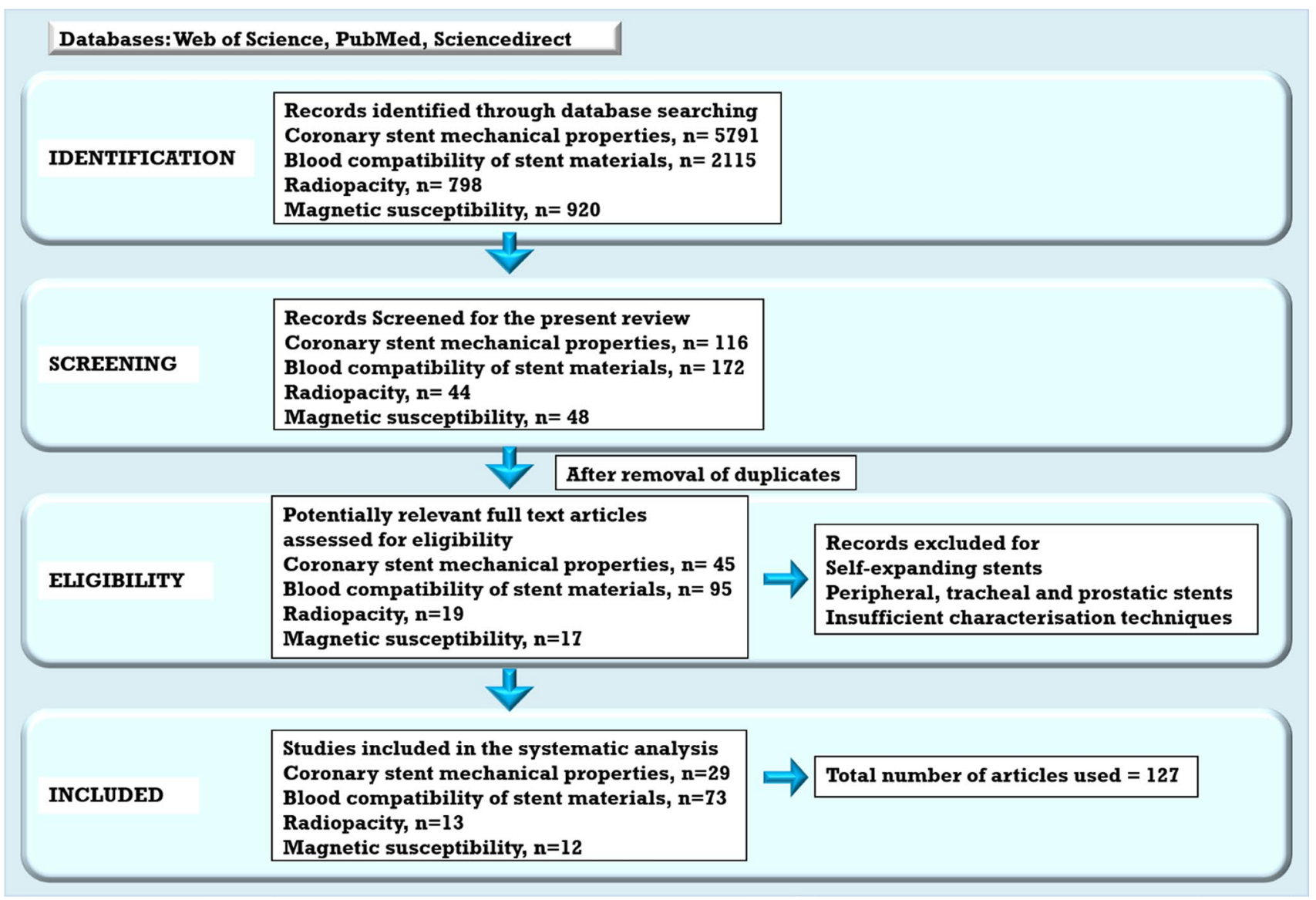

Fig. 2 Flow chart showing search strategy used for systematic reviewing in accordance with PRISMA

between the mechanical properties which influence the navigating, expanding and eventual fracture behavior, as well as the consequent working mismatch of stent material with surrounding tissue is of utmost importance.

Apart from mechanical properties of the stent, the hemocompatibility of the stent materials as well as the stent surface also dictates its long-term success. Hemocompatibility can be defined as the capability of implanted material to remain in the blood environment without eliciting activation of coagulation cascade, compliment system, and specific immunological pathways. Such incompatibility in blood can lead to adverse reactions leading to thrombosis, emboli nucleation and migration (leading to stroke), destruction of blood components, and neointimal hyperplasia resulting in ISR [30, 31]. Nevertheless, second-generation DES have emerged as a promising technology for reducing restenosis rates compared to first-generation DES and BMS, and it is often associated with LST, neoatherosclerosis, and target lesion revascularization [32-35].

In addition to mechanical and blood perspectives, the physical parameters such as radiopacity and magnetic susceptibility possess paramount clinical significance. The
ISAR-STEREO clinical trials demonstrated that risks associated with restenosis could be reduced up to $42 \%$ by using thin strutted stents $[36,37]$. Nonetheless, this development of thin struts is associated with a conflicting requirement of improved visibility or radiopacity. Moreover, non-interpretable imaging makes stent maneuvering difficult in case of small diameter vessel $(<3 \mathrm{~mm})$ and children with congenital heart diseases [38, 39]. The efficacy of magnetic resonance imaging is often hindered by magnetic artefacts produced by stent material producing signal losses and unclear images [40].

Hence, the first part of discussion of this article seeks to review the desired mechanical properties of coronary stent material which can significantly affect the clinical outcome. The second part of this review presents in-depth the basic mechanism of blood coagulation leading to thrombosis, stent surface response to thrombogenic events, and surface modification of stents. Finally, the last section of this review discusses the physical fundamental factors that are associated with improved radiopacity and reduced magnetic susceptibility. 


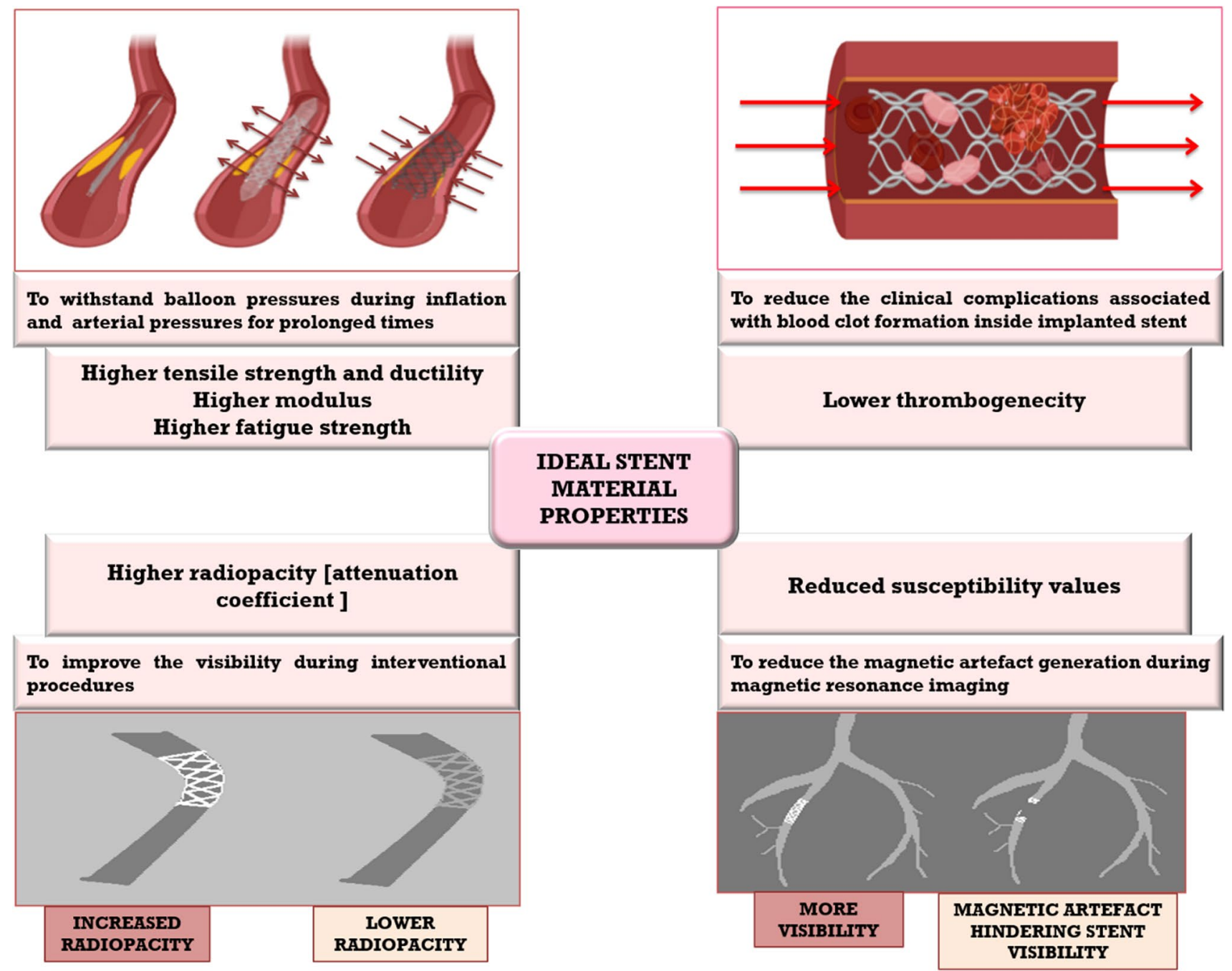

Fig. 3 Properties selected as rationale for ideal stent material

\section{Discussion}

\section{Mechanical properties}

For balloon expandable stents, the material should primarily meet requirements such as increased ductility for crimping onto the balloon catheter assembly, adequate tensile strengths and sufficient radial hoop strength with higher elastic modulus for maintaining minimal recoil, and adequate durability to resist fatigue failure due to pulsatile arterial pressures. Ductility refers to a material's property to be drawn or plastically strain without fracture and tensile strength is the maximum mechanical stress a material can withstand when subjected to a tensile force [41]. The elastic modulus or Young's modulus is a measure of the material stiffness or resistance to elastic deformation and is determined by the ratio of stress to strain in the elastic regime [42]. Various clinical complications resulting from inferior mechanical properties of stent materials such as stent malapposition, conformability problems, fracture, fretting wear, underexpansion, and overexpansion are summarized in Table 1.

\section{Tensile properties}

The tensile properties of BMS materials are, in general, well documented [48, 49]. Larger plastic deformation (to reach required size during deployment), strain hardening, higher tensile strength, radial strength, and elastic modulus values make stainless steel and cobalt alloys the gold standard materials for balloon expandable coronary stent applications. These properties are vital for preventing arterial recoil and negative remodelling. In the case of recoil, higher balloon pressures are required for compensating loss of lumen patency which can subsequently lead to arterial injury [50]. The use of high-strength materials for 
Table 1 Clinical complications associated with inferior mechanical properties

\begin{tabular}{|c|c|c|c|}
\hline Complication & Definition & Figure & Ref. \\
\hline $\begin{array}{l}\text { Strut } \\
\text { malapposition }\end{array}$ & $\begin{array}{l}\text { Separation of at least one stent } \\
\text { strut from the innermost layer } \\
\text { of the arterial wall with } \\
\text { evidence of blood behind the } \\
\text { strut, without involvement of } \\
\text { side branches. Fig.T1a: Stent } \\
\text { strut malapposition. }\end{array}$ & & [43] \\
\hline Conformability & $\begin{array}{l}\text { Degree to which a deployed } \\
\text { stent can bend along its } \\
\text { longitudinal axis. } \\
\text { Fig.T1b: Stent conformability } \\
\text { at regions of tortuous arterial } \\
\text { regions }\end{array}$ & & [44] \\
\hline Stent fracture & $\begin{array}{l}\text { Complete/ incomplete } \\
\text { separation of a stent strut. } \\
\text { Fig.T1c: A complete transverse } \\
\text { linear type stent fracture. }\end{array}$ & & [45] \\
\hline $\begin{array}{l}\text { Fretting wear } \\
\text { and fretting } \\
\text { corrosion }\end{array}$ & $\begin{array}{l}\text { Occurs due to the interaction of } \\
\text { overlapping stent surfaces in } \\
\text { close contact undergoing } \\
\text { micromotion in the blood } \\
\text { environment. } \\
\text { Fig.T1d: Physical damage of } \\
\text { the } 316 \mathrm{~L} \text { stainless steel stent } \\
\text { surface due to fretting } \\
\text { corrosion }\end{array}$ & & [46] \\
\hline $\begin{array}{l}\text { Overexpansion } \\
\text { and } \\
\text { underexpansion }\end{array}$ & $\begin{array}{l}\text { Stent overexpansion can lead } \\
\text { to neointimal hyperplasia } \\
\text { whereas underexpansion can } \\
\text { result in thrombosis and } \\
\text { restenosis. } \\
\text { Fig.T1e: Overexpansion of } \\
\text { stent limiting stent expansion } \\
\text { and apposition. }\end{array}$ & & [47] \\
\hline
\end{tabular}


balloon expandable stent materials possesses multi-faceted outcomes [51]. On one side, the use of materials with higher yield strength can improve the stent performance by (a) improving stent radial strength and radial stiffness thereby (b) reducing the stress on the arterial wall and the material strain. On the contrary, this comes at the expense of (a) an increased recoil associated with stent and (b) reduced flexibility of the stent material.

316L SS (austenitic chromium-nickel stainless steel with lower carbon content) is the conventional material used for stents that meld features such as enhanced strength, modulus, and ductility (plastic strains as high as $20-30 \%$ ). One of the limitations associated with firstgeneration DES which utilized 316L SS as the stent platform was increased strut thickness in the range of $130-140 \mu \mathrm{m}$, as the stent radial strength and radiopacity being dependent on strut thickness. As mentioned above, the requirement of reduced strut thickness is a pivotal factor in minimizing restenosis rates which concomitantly reduces the radiopacity. In the quest of developing steels with reduced strut thickness and improved radiopacity, Craig et al. added $0-10 \% \mathrm{Pt}$ with stainless steel to form platinum-enhanced radiopaque stainless steels and the mechanical testing revealed that $10 \%$ Pt addition resulted in favorable yield strength (355 MPa) for stent application. However, other mechanical properties such as ductility and work hardening rate were least improved [52]. Apart from these, mounting concerns are expressed over the adverse effects of the nickel (Ni) content in 316L SS which can elicit carcinogenic as well as genotoxic effects. Moreover, use of this class of stents reported the incidence of ISR in patients with hypersensitivity towards $\mathrm{Ni}$ and molybdenum (Mo) [53]. Considering the potential risk of nickel content, several researchers are working on the development of high nitrogen nickel-free austenitic stainless steel (HNASS), which exhibited high strength with acceptable ductility and anti-restenosis for stent applications [54, 55]. Hence, it is highly imperative to develop ultra-thin strut $\mathrm{Ni}$-free stainless steel compositions with optimized stent properties via tailored metallurgical routes.

Cobalt-chromium $(\mathrm{CoCr})$ alloy stents have excellent radial strength, high elastic modulus (190-230 GPa) and can be used to form ultra-thin stent struts. Among different cobalt-chrome alloys, L605 (Co-20Cr-15 W-10Ni$3 \mathrm{Fe}-1.5 \mathrm{Mn}$, ASTM F90), MP35N (Co-20Cr-35Ni-10Mo, ASTM F562), and elgiloy (Co-20Cr-15Ni-7Mo-2Mn-16Fe, ASTM F-1058) are commonly used for stent fabrication. Second-generation DES with Co-Cr platforms are developed with reduced strut thickness $(70-90 \mu \mathrm{m})$ while maintaining better compressive strength and minimal recoil. More recent introduction of Co-Cr-based ultra-thin strut sirolimuseluting DES Orsiro $(60 \mu \mathrm{m})$, MiStent $(64 \mu \mathrm{m})$, and BioMime $(65 \mu \mathrm{m})$ has exhibited improved clinical outcomes [56].
Precious metals such as platinum, iridium, silver, and palladium are also pertinent for coronary stent applications in terms of enhanced visibility and inert behavior. However, these alloys are often associated with inferior mechanical properties with comparatively higher degrees of stent recoil. Pt-Cr have demonstrated its efficacy as a DES backbone with strut thickness in the range of 70-86 $\mu \mathrm{m}$ (Promus stent) [57]. Another class of Pt-Ir alloy stent is particularly advantageous for congenital heart diseases as it possesses excellent visibility, MRI compatibility, and reduced risk of vessel trauma [58, 59]. Apart from these, ABI alloy (silver and palladium alloy) is another precious metal stent alloy, which exhibited mechanical properties comparable to that of $316 \mathrm{~L}$ $\mathrm{SS}$, in which palladium addition assisted in improving the mechanical properties of pure silver [180].

As mentioned earlier, besides mechanical properties, magnetic susceptibility is of prime importance for successful interventional procedures. Owing to its lower magnetic susceptibility and enhanced biocompatibility, niobium alloys are also gaining increased attention for stent applications. Niobium-based alloy (Nb-28Ta-3.5W-1.3Zr) developed by O'Brien et al. exhibited an appreciable yield strength (350 MPa) along with an elongation of about $25 \%$ and the developed stent prototype exhibited minimal recoil of $2.2 \%$ and compression strength of $0.22 \mathrm{~N} / \mathrm{m}$ attributed to the solid solution strengthening effect of both tantalum and tungsten [61]. Studies on varying compositions of $\mathrm{Nb}-\mathrm{xTa}-2 \mathrm{Zr}$ $(30 \leq x \leq 70)$ revealed that an optimal composition of $\mathrm{Nb}-60 \mathrm{Ta}-2 \mathrm{Zr}$ exhibited an elastic modulus of $142 \mathrm{GPa}$, a yield strength of $330 \mathrm{MPa}$, and an elongation of approximately $24 \%$ suitable for stent applications [62]. These properties can be further enhanced with suitable thermomechanical procedures as beta $\mathrm{Nb}$ alloy is found to respond positively to thermomechanical processing [61]. Thus, there is good potential for these niobium-based alloys and further work is warranted, thereby facilitating their future commercialization.

Titanium (Ti) alloys, particularly beta Ti alloys, are extensively used for orthopedic, dental, and cardiovascular applications owing to its superior biocompatibility and corrosion resistance [63]. Moreover, these alloys possess enhanced MRI compatibility ascribed to their reduced magnetic susceptibility. Despite these advantages, titanium usage for balloon expandable coronary stents is hindered by the lower values of elastic modulus, plastic deformation ability, and density. Even though a lower modulus is advantageous for orthopedic applications, in the case of balloon expandable stents, this reduced modulus can lead to higher elastic recoil leading to clinical complications [64]. Secondly, in spite of the fact that titanium alloys possess yield strength values comparable to those of stainless steel and cobaltchromium-based alloys, they exhibit lower ultimate tensile strengths associated with a shorter plastic deformation range. 
Consequently, there is an increased risk of fracture, when deformed beyond yield strength values, leading to dynamic failure during long-term service. Finally, lower density renders lower X-ray visibility of titanium reducing the radiopacity. An initial study to enhance the elastic modulus and radiopacity of three beta Ti alloys (Ti-50Ta, Ti-45Ta-5Ir, and Ti-17Ir) was conducted by O'Brien et al. [65]. Among these alloys, eutectoid composition Ti-17Ir exhibited modulus enhancement (128 GPa) through a composite stiffening effect provided by $\mathrm{Ti}_{3} \mathrm{Ir}$ precipitation and iridium addition significantly enhanced the radiopacity of the material. Apart from these Ti-Ir alloys, binary Ti-Mo-, ternary Ti-Mo-W-, and Ti-Nb-Mo-based alloys were designed following the Morinaga model [66, 67]. Tensile testing of these Ti-12Mo, Ti-9Mo-6 W, and Ti-16Nb-8Mo exhibited promising plastic deformation with elongation of about 46,43 , and $45 \%$, respectively. There should be more detailed investigation to explore the possibilities of increasing the modulus of beta $\mathrm{Ti}$ alloys while maintaining adequate ductility for balloon expandable stent applications.

Among the BAS, magnesium $(\mathrm{Mg})$, iron $(\mathrm{Fe})$, and zinc (Zn)-based materials are being investigated for optimum rate of degradation while maintaining required mechanical integrity. $\mathrm{Mg}$ alloys are associated with inherent rapid corrosion in the blood environment and premature loss of structural integrity (insufficient mechanical strength) accompanied by the formation of hydrogen gas pockets [68]. On the contrary, Fe alloys exhibit slower corrosion rates [69] substantially below the clinical requirement and the retention of ironbased corrosion products in the physiological environment can lead to metabolic problems [70]. Zn alloys are reported to possess the potential to overcome the limitations associated with $\mathrm{Mg}$ - and Fe-based alloys for efficient bioabsorbable stent applications. Even though Zn displays a nearly ideal corrosion rate compared to $\mathrm{Mg}$ and $\mathrm{Fe}$ alloys relevant for stent applications [71], from a mechanical perspective, the strength-ductility values of this class of $\mathrm{Zn}$ alloys raise clinical concerns. Current research is focused towards improving the limitations associated with all these three classes of alloys by proper alloying and tailored thermomechanical processing routes for ideal stent material. It should also be pinpointed that even though standardized guidelines for mechanical testing are available for non-degradable (metals and alloys) as well as bioabsorbable polymers, a quantitative standard to assess the mechanical properties of BAS materials is yet to be developed. Tensile properties of relevant stent materials are listed in Table 2. Computational numerical methods can also assist in the stent design and performance evaluation by optimizing the geometrical and material features of stents [72]. With rapidly increasing computational power and rise of robust finite element approaches, there is a considerable improvement in the field of simulating the stent deformation and deployment processes [73, 74].

\section{Fatigue}

As coronary stents are subject to cyclic loading, fracture of the coronary stents due to fatigue leads to loss of radial support for arterial walls and perforation of the arterial lumen by struts leading to clinical complications. Owing to continuous heart beating, implanted metallic stent tubes are subjected to systolic and diastolic sinus rhythms of arterial walls pulsing typically 72 plus times a minute as shown schematically in Fig. 4. Generally, stents are designed to maintain their structural integrity for a time period of 10-15 years (400-600 million of loading cycle) in a high cycle fatigue regime. In order to endure this, a very high fatigue life should be exhibited by any material used for fabricating stents and the various factors affecting the fatigue life are discussed in the following section.

Clinical factors such as stented vessel pathology and typical clinical deformation modes such as vascular calcification, anatomical locations with bend, and cases of overlapping stents are very critical problems which can significantly affect the fatigue life of the material. A clinical trial involving 686 patients was conducted to examine the effects of stent fatigue and its clinical significance [46]. It was revealed that aortic pulsations can generate sufficient stress for the development of microcracks and morphology of the recipient vessel shape plays a significant role in determining the structural integrity of the implanted metallic stent. Halwani et al. thoroughly evaluated fracture and biomechanical abrasion of stents obtained from autopsy [85]. Six out of the seven cases were found to have fractures due to high cycle fatigue. Vessel calcification was evident in most of the cases and main fracture locations were strut connecting points. This work also exposed the requirement of a superior understanding of diseased arterial vessel properties for optimized fatigue testing design.

Secondly, a microstructure sensitive design approach is highly essential for developing a stent material with improved fatigue properties. Fatigue design for different applications is established to be dependent on grain size effect. Various mechanical properties of metallic materials are dependent on its grain which is an aggregate of three-dimensional growth of unit cells separated by grain boundary. A coarser grain size usually results in reduced strength and increased ductility, whereas a fine grain size will increase the strength at the expense of diminishing ductility [86]. Fine grains exhibit resistance to fatigue crack initiation, whereas coarser ones are utilized for components which are more prone to fatigue crack growth. Hence, in the case of stents, where fatigue life is dominated by fatigue crack initiation, fine grains are preferred. Sweeney et al. extensively worked on the development of a micromechanical model comparable to stent strut dimensions for evaluating fatigue characteristics of Co-Cr-based alloys and 
Table 2 Mechanical properties of relevant metallic stent materials

\begin{tabular}{|c|c|c|c|c|c|}
\hline Material & $\begin{array}{l}\text { Yield } \\
\text { strength } \\
(\mathrm{MPa})\end{array}$ & $\begin{array}{l}\text { Ultimate tensile } \\
\text { strength }(\mathrm{MPa})\end{array}$ & $\begin{array}{l}\text { Percent } \\
\text { elongation } \\
(\%)\end{array}$ & $\begin{array}{l}\text { Elastic } \\
\text { modulus } \\
(\mathrm{GPa})\end{array}$ & Ref. \\
\hline \multicolumn{6}{|l|}{ Stainless steels } \\
\hline 316L SS, annealed, ASTM F138 & 190 & 490 & 40 & 193 & [75] \\
\hline Ni-free SS, annealed, ASTM F2229 & 586 & 931 & 52 & 200 & [76] \\
\hline \multicolumn{6}{|l|}{ Co-Cr alloys } \\
\hline L605, ASTM F90 & 500 & 1000 & 50 & 243 & \multirow[t]{3}{*}[77]{} \\
\hline MP35N, ASTM F562 & 414 & 930 & 45 & 233 & \\
\hline Elgiloy, ASTM F1058 & 450 & 950 & 45 & 221 & \\
\hline \multicolumn{6}{|l|}{ Precious metal-based alloys } \\
\hline Pt-33Cr, unannealed & 1011 & 1317 & 5.5 & 191 & [78] \\
\hline Pt-Ir & 200 & 340 & 25 & 150 & [79] \\
\hline \multicolumn{6}{|l|}{ Nb and Ta-based alloys } \\
\hline $\mathrm{Nb}$ & 105 & 195 & 25 & 103 & \multirow[t]{2}{*}{ [80] } \\
\hline $\mathrm{Nb}-28 \mathrm{Ta}-3.5 \mathrm{~W}-1.3 \mathrm{Zr}$ & 339 & 416 & 25.2 & 128 & \\
\hline $\mathrm{Nb}-60 \mathrm{Ta}-2 \mathrm{Zr}$ (forged + annealed) & 332 & 474 & 24 & 142 & [81] \\
\hline $\mathrm{Ta}$ & 138 & 207 & 25 & 185 & [79] \\
\hline \multicolumn{6}{|l|}{ Ti-based alloys } \\
\hline Commercially pure $\mathrm{Ti}$ & $170-241$ & $240-331$ & 30 & 103 & \multirow[t]{5}{*}[82]{} \\
\hline Ti-6Al-4V & $830-924$ & $900-993$ & 14 & 114 & \\
\hline Ti-50Ta & 931 & 1151 & 3 & 90 & \\
\hline Ti-45Ta-5Ir & 717 & 641 & 18 & 72 & \\
\hline Ti-17Ir & 903 & 958 & 14 & 109 & \\
\hline \multicolumn{6}{|l|}{ Mg-based } \\
\hline Pure $\mathrm{Mg}$ & 20 & 86 & 13 & 41 & \multirow[t]{2}{*}{ [75] } \\
\hline WE-43 extruded, T5 & 195 & 280 & 2 & 44 & \\
\hline WE-43 tempered, T6 & 170 & 220 & 2 & 44 & [9] \\
\hline AZ31, extruded & $125-135$ & 235 & 7 & 45 & [11] \\
\hline ZW21, extruded & 200 & 270 & 17 & & \\
\hline $\mathrm{Mg}-\mathrm{Zn}$ & 170 & 280 & 19 & 42 & \\
\hline \multicolumn{6}{|l|}{ Fe-based } \\
\hline $\mathrm{Fe}-35 \mathrm{Mn}$, annealed & 230 & 430 & 30 & 53 & \multirow[t]{3}{*}{ [75] } \\
\hline Fe-10Mn-1Pd alloy, heat treated & $850-950$ & $1450-1550$ & $2-8$ & 60 & \\
\hline $\begin{array}{l}\text { Fe-30Mn-6Si alloy, solution treated } \\
\text { Zn-based }\end{array}$ & 180 & 450 & 16 & 60 & \\
\hline $\mathrm{Zn}$, as-rolled & 30 & 49.5 & 5.72 & - & \multirow[t]{2}{*}{ [83] } \\
\hline $\mathrm{Zn}-4 \mathrm{Cu}$ & 250 & 270 & 51 & - & \\
\hline $\mathrm{Zn}-1 \mathrm{Sr}$, as-rolled & 188 & 229 & 19.69 & - & [84] \\
\hline $\mathrm{Zn}-1 \mathrm{Mg}-0.1 \mathrm{Mn}$, as-rolled & 195 & 299 & 26.07 & - & \\
\hline
\end{tabular}

proved that fine-grained materials possess superior fatigue lives than coarser ones $[87,88]$. It is postulated that this improvement might be due to the increased hardening of the fine-grained structure owing to the presence of immobile geometrically necessary dislocations (GNDs) hindering the dislocation motion [89]. All these studies reaffirmed the necessity of microstructure sensitive prediction methods that investigate fatigue life when designing stents. Apart from microstructure, surface finish is another predominant factor affecting the endurance of a stent material, as the defects on the surface can act as points of crack nucleation. High cycle regime studies for thin-walled L605 stents proved the influence of surface finishing procedures in improving the fatigue performance to about $40 \%$ [90].

Apart from microstructure and surface finish, strut dimensions play a significant role in fatigue life determination and its effect has been reported by Azaouzi et al. on AISI316L stainless steels for balloon expandable stent applications [91]. The fatigue life was found to be dependent on strut dimensions, as grains near to the boundaries of the strut deform more when compared to interior strut grains which are more constrained by the 
Fig. 4 Fatigue loading on stent walls by arterial wall

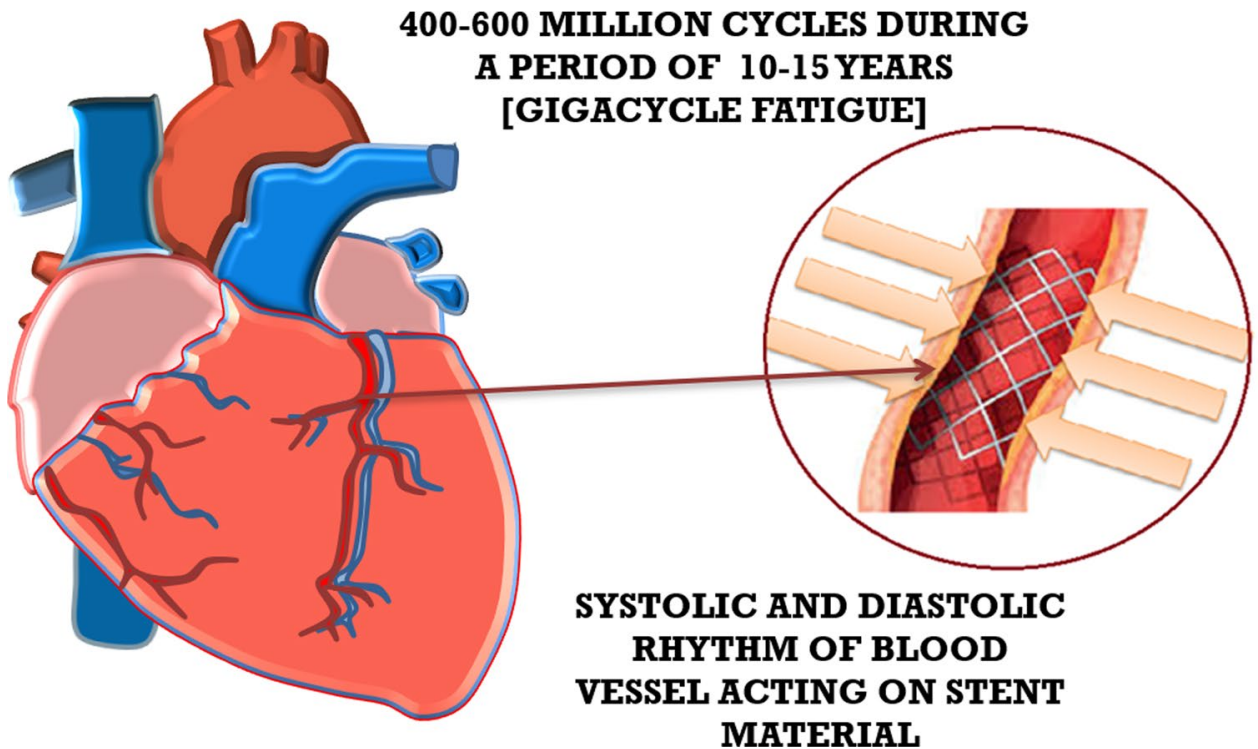

surrounding grains. In another study involving stainless steel and cobalt chromium stents subjected to accelerated pulsatile loading tests, fractures were observed in regions having curvature and along connecting links of stent platform [92]. In addition to this, accelerated pulsatile loading on L605-cobalt chromium alloy was performed based on Goodman criteria [93]. Cyclic loading induced slip bands located on the curves of the struts, and were attributed to the distribution of high alternating stresses in that area. Pertinent works related to fatigue testing of stents are summarized in Table 3. As per the FDA (document number 1545) and ASTM (ASTM-F2477-07) directive, the in vitro fatigue testing of vascular stent materials should be performed using fully processed clinical quality stent material in a stimulated pulsatile condition [94]. BAS materials are more prone to corrosion-fatigue associated with the metal damage under cyclic loading. Recently published ASTM WK61103 standard outlines the standardized procedure to assess the corrosion-fatigue evaluation for absorbable metallic devices [95].

Furthermore, most of the cardiovascular devices are associated with several bio-tribological problems which can lead to device failures or other biocompatibility issues [96]. In the case of tortuous arterial regions and overlapping stents, biotribology is significant which can lead to fretting wear. These overlapping stents, which are usually implanted in cases of long diffuse coronary lesions and in the regions of tortuous blood vessels, exhibited mechanical fretting owing to the micromotion between overlaying surfaces. Moreover, the pulsed arterial blood flow can also exert different shear forces to two overlapping stents eventually ensuing stent failure.

\section{Hemocompatibility}

Hemocompatibility is the term used to define the compatibility of an implanted material in the blood environment. When the human blood comes in contact with an external material, hemostasis response is activated leading to inflammatory reactions, eventually leading to blood clotting or thrombosis. A mechanistic understanding of the complex cascades associated with this activation process, and one that is triggered at the blood-stent interface, is essential for developing new materials for coronary stent applications. Despite being investigated by various researchers; thrombosis phenomenon still holds a controversial element which requires a refined understanding.

\section{Stent thrombosis}

One of the key aspects of hemocompatibility for stent applications is thrombogenecity. As the stents are inserted into the blood vessel, vascular injury may happen (as shown in Fig. 5a) disrupting the endothelial layer inciting the formation of a hemostatic plug composed of platelets and fibrin network. The initial step in thrombus formation is the adsorption of proteins such as collagen (from subendothelium), fibrinogen, and fibronectin (from blood plasma) on the implanted stent surface prior to platelet adhesion, activation, and aggregation. This protein adsorption mediates the biological response by the diffusion of other blood serum proteins to the stent surface forming strong bonds at specific sites [97, 98].

These adsorbed proteins form a bridging link between surface end receptors in platelets and collagen in the 
Table 3 Fatigue test conditions of stent materials and fractographs $[R T$ room temperature]

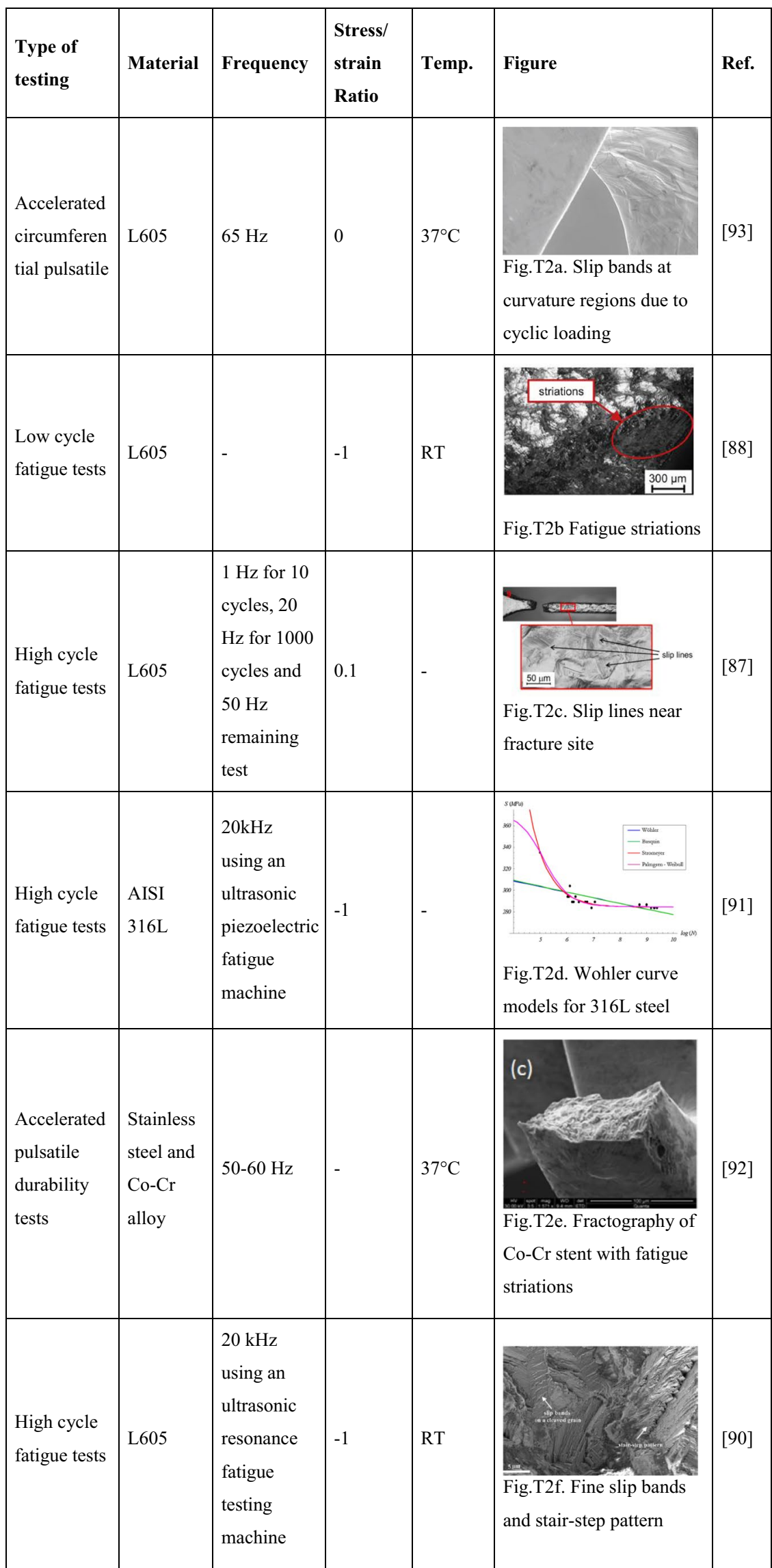




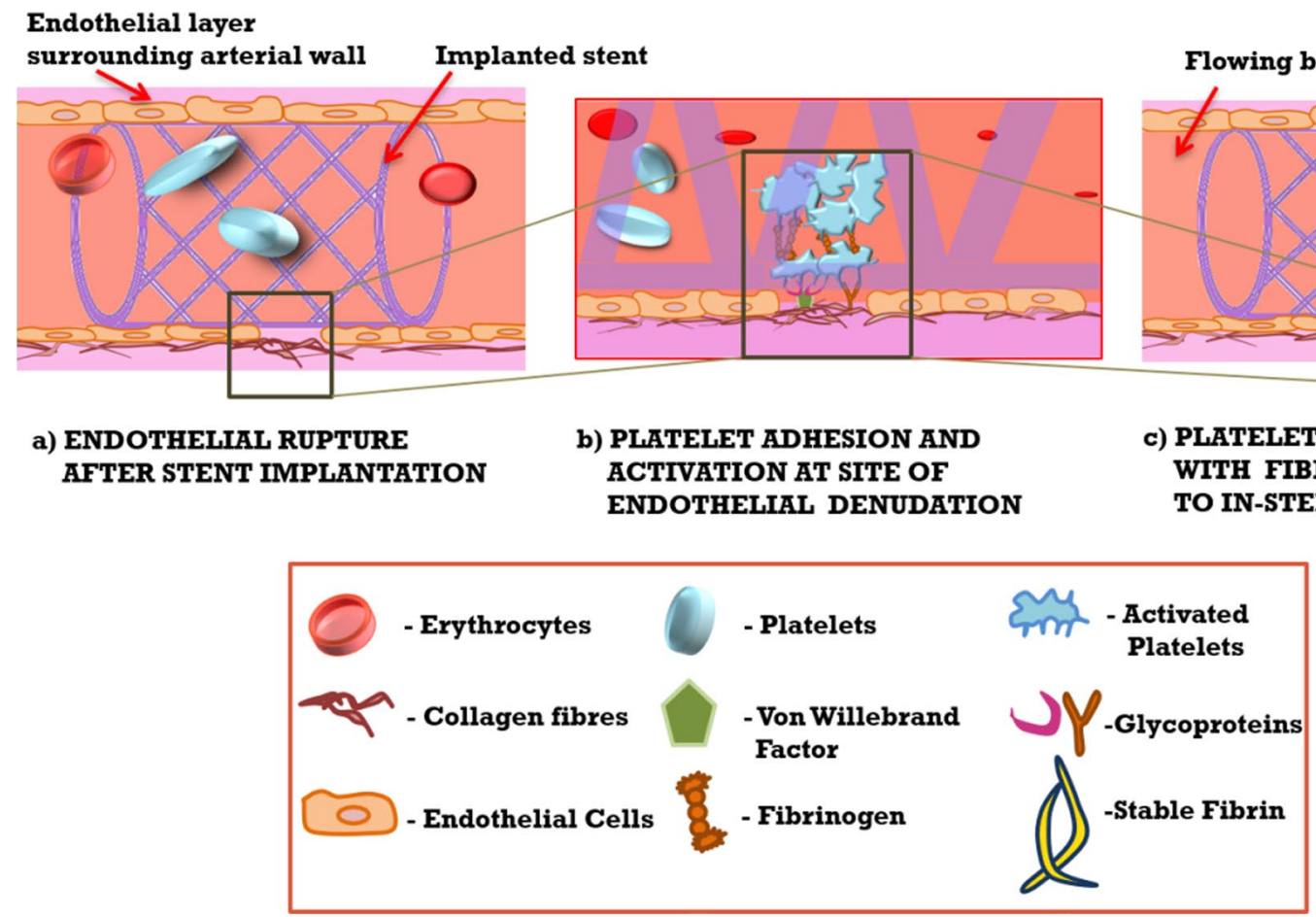

Fig. 5 Stent thrombosis schematic. (a) Implanted stent inside an artery can lead to endothelial damage (as shown in inset). (b) At the site of endothelial denudation, platelets adhere to the exposed sub-

subendothelium thereby initiating platelet adhesion at the region of vessel injury (schematically illustrated in Fig. 5b). Initially, surface receptor GPIb within the platelet membrane attaches to exposed collagen and this process is mediated by a glycoprotein, von Willebrand factor [99, 100]. During the activation stage, platelet granules release secondary platelet agonists particularly thromboxane and adenosine diphosphate (ADP) which assist in aggregation of platelets. After the platelets are activated, the surface receptor GPIIbIIIa attaches to fibrinogen leading to platelet aggregation forming a friable occlusive plug [101]. This will modify to a firm thrombus formation as thrombin deposits a fibrin network (as represented in Fig. 5c) via an activation cascade which will be described in the following section. The adhered platelets will also activate a platelet immune complex, which signals further attachment of leukocytes [102].

As standardized by the Academic Research Consortium, the stent thrombosis can be categorized based on the timing as acute (within $24 \mathrm{~h}$ of stent implantation), subacute ( $24 \mathrm{~h}$ to 30 days), late ( 30 days to 1 year), and very late (after 1 year) [103]. Within 30 days after stent implantation, early stent thrombosis occurs due to the incomplete reendothelialization of the inserted stent and dual antiplatelet therapy (DAPT) should be continued during this period to inhibit platelet activation. Late and very late stent thrombosis (more associated with first-generation DES compared to endothelial collagen fibers via von Willebrand factor and other glycoproteins and get activated. (c) Accumulation of activated platelets with the aid of stable fibrin polymers leading to thrombus formation

BMS [104]) may be caused by delayed endothelialization, fibrin deposition, and inflammation of blood vessel [105].

Systematic in vitro and in vivo studies followed by clinical trials should be conducted to ensure both safety and functionality of the implanted stent. In order to characterize the hemocompatibility of stent surfaces, various in vitro tests are conducted in accordance with ISO 10993-4 [106]. Hemolysis testing is one of the general tests in which the increased quantity of free hemoglobin is employed as an indicator of erythrocyte destruction. Hemolysis refers to the rupture of the erythrocyte $(\mathrm{RBC})$ membrane and consequent release of hemoglobin to surrounding fluid [107]. Platelet activation is prevented by the vascular endothelium via ectonucleotidases, by breaking down adenosine triphosphate and adenosine diphosphate, thrombomodulin by inactivating thrombin, and the release of prostaglandin and nitric oxide [108]. Hence, rapid endothelialization after stent implantation is another critical factor to assess the efficiency of a stent material. Once the stent is inserted inside the blood vessel, endothelial destruction occurs during the stent expansion and resulting exposure to smooth muscle cells can lead to ISR due to the vessel diameter narrowing down $>50 \%$ [109]. Platelet adhesion tests are also performed to ensure reduced platelet adhesion and activation which will otherwise result in thrombus formation. Apart from endothelial cells and platelets, blood plasma proteins which will adsorb 
to the implanted stent surface play a significant role in mediating stent thrombosis. Out of the various plasma proteins, fibrinogen mediates platelet adhesion whereas albumin binding on the stent can passivate the surface from fibrinogen, thereby reducing platelet adhesion and activation [19]. Newly developed stent surfaces are tested for endothelial cell, smooth muscle cell proliferation, blood plasma protein interactions, and platelet adhesion/activation and an ideal one should accelerate re-endothelialization while at the same time mitigating smooth muscle cell proliferation as well as platelet activation. Most importantly, in order to gain more insights into the biological processes occurring under blood flow, dynamic blood flow studies should be performed to understand the cellular and protein behavior [110]. For the in vivo testing of coronary stents, preferred animal models are the domestic crossbred or miniature swine model or the rabbit iliac artery model, reported in comparative studies [111].

\section{Blood coagulation pathways}

The blood coagulation cascade consists of a series of zymogen-enzyme conversions, initiated by intrinsic or extrinsic pathways and eventually, a common pathway will result in thrombus (FIIa) formation as schematically represented in Fig. 6 . The intrinsic pathway is initiated by the conversion of the Hageman factor (FXII) to activated FXIIA as a result of the surface contact activation process. FXIIA along with prekallikrein, high molecular weight kininogen (HMWK), and thromboplastin antecedent (FXI) assembles to form a contact activation complex [112]. Following this, sequential activation of coagulation factor IXA occurs, which along with activated factor VIIIA accelerates factor $\mathrm{X}$ activation leading to common pathway.

The exposure of flowing blood to tissue factor (TF) initiates the extrinsic coagulation cascade [113]. Tissue factor is a glycoprotein present in the subendothelial layer of the arterial wall, which under normal conditions has no contact with blood. During endothelial injury induced by the placement of the stent, this TF is exposed to proconvertin (factor VII). Factor VII attaches to the phospholipids from TF to activate TF-VIIa complexes and these complexes will activate factor $\mathrm{X}$ to $\mathrm{XA}$ initiating the common pathway as mentioned above.

In the common pathway, the activated Stuart-Prower factor (factor XA) bound to cofactor VA, calcium, and platelet phospholipid, termed as prothrombinase complex, converts prothrombin to thrombin. This thrombin hydrolyses fibrinogen to insoluble fibrin monomers by clipping off two peptides fibrinopeptides A and B. Meanwhile activated factor XIIIA stabilizes the clot by forming amide bonds between side chains of these fibrin monomers. Eventually, this fibrin

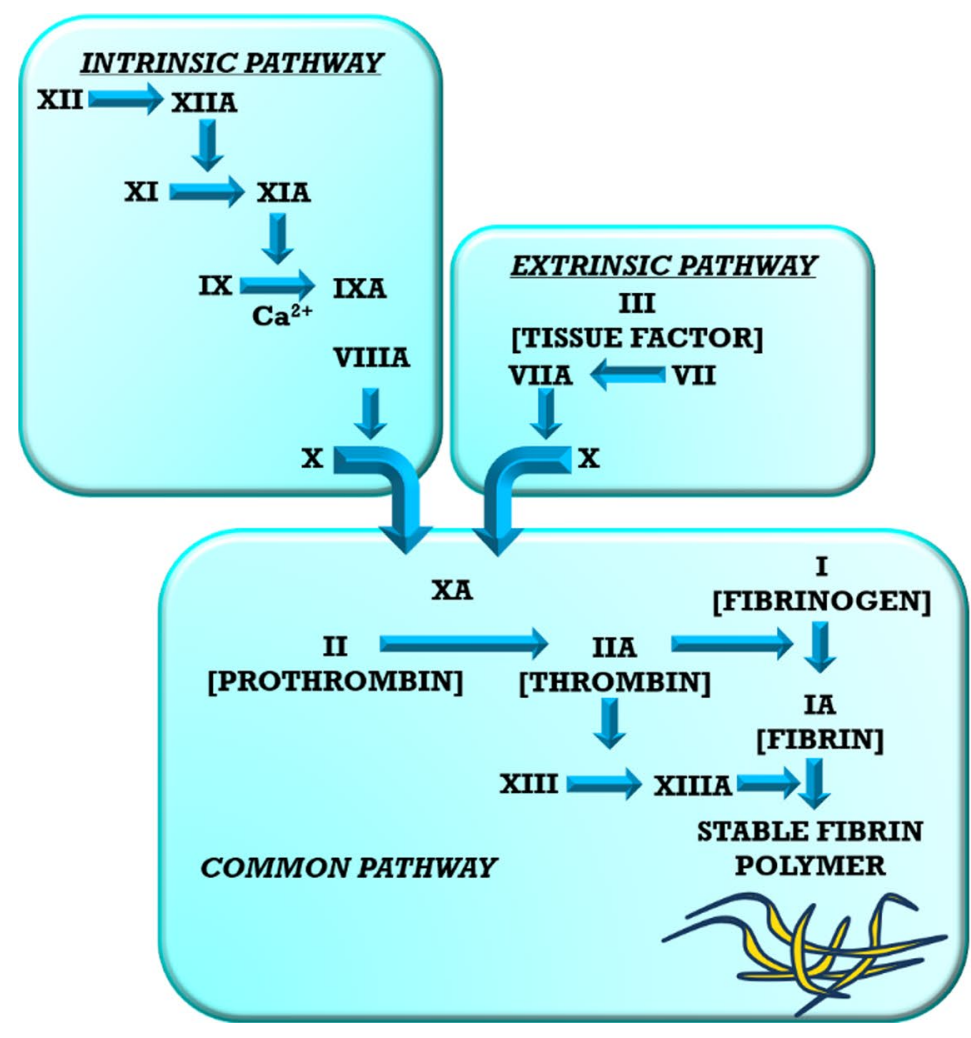

\begin{tabular}{|ll|}
\hline FACTOR I & - FIBRINOGEN \\
FACTOR II & - PROTHROMBIN \\
FACTOR III & - TISSUE FACTOR \\
FACTOR IV & - CALCIUM \\
FACTOR V & - PROACCELERIN \\
FACTOR VI & - ACCELERIN \\
FACTOR VII & - PROCONVERTIN \\
FACTOR VIII & - ANTIHEMOPIHIC FACTOR \\
FACTOR IX & - CHRISTMAS FACTOR \\
FACTOR X & - PROTHROMBINASE \\
FACTOR XI & - PLASMA THROMBOPLASTIN \\
& ANTECEDENT \\
FACTOR XII & - HAGEIMAN FACTOR \\
FACTOR XIII & - FIBRIN STABILISING FACTOR \\
\hline
\end{tabular}

Fig. 6 Blood coagulation pathways 
network stabilizes the platelet-rich thrombus. One of the critical problems associated with these pathogenic thrombi is that the powerful antithrombotics used to treat these thrombi can impair bleeding in damaged healthy vessels. Ongoing clinical trials with new generation of antiplatelet and anticoagulant drugs have shown considerable promise towards these clinical complications [114].

\section{Surface response}

Apart from the bulk material properties, the stent surface plays a pivotal role in tailoring the blood response. Surface potential, roughness, morphology, surface oxide layer stability, and surface energy are the major determinants in the protein adsorption process. In most cases, the outcome is dependent on the combination of these multiple factors. In addition to these stent surface characteristics, the behavior of the blood proteins interacting with the surface should also be given consideration while designing a surface.

The incidence of thrombosis is highly dependent on the material's surface potential. The net electrical charge difference between blood components and the stent surface can initiate thrombotic events. Native blood vessels and blood cells are all negatively charged in the physiological environment. Hence, under normal conditions, no blood clotting occurs as the intravascular surface (endothelium) will repel the blood platelets and proteins. Most of the metallic stents possess a positive surface charge which attracts these negatively charged blood components leading to thrombosis reactions. Zeta potential measurements represent an effective method to measure the surface charge of stent materials $[115,116]$. Biomimetic surface functionalization of a $\mathrm{CoCr}$ alloy surface using negatively charged peptides improved endothelial cell adhesion and proliferation [117]. In the case of stainless steel and gold stents possessing an increased electrochemical surface potential, electron transfer to blood proteins can lead to neointimal hyperplasia. Animal studies using titanium-nitride-oxide-coated stainless steel stents possessing a lower surface potential resulted in significant reduction of neointimal hyperplasia [118].

Surface roughness could significantly alter stent thrombogenecity as a smoother surface finish minimizes platelet activation and aggregation inside stents [119]. Irregularities on the stent surface induce potential gradients thereby impeding surface passivation leading to thrombosis. Linneweber et al. found that platelet adhesion was significantly higher for 0.2 and $0.4 \mu \mathrm{m}$ compared to a $0.05-\mu \mathrm{m}$ surface [120]. A topographically patterned $\mathrm{CoCr}$ alloy surface with varying periodicities and depths combined with modified oxide layer properties is reported to accelerate endothelial recovery and avoid surface thrombosis [121]. Mimicking the natural vascular tissue by creating a nanometer topography on the stent surface is reported to invoke advantageous cell responses for stent applications [122]. Another factor, surface oxide layer stability, is vital as it can act as a barrier to ion release from the underlying bulk metal. In vivo and in vivo studies by Shih et al. have demonstrated higher thromboresistance for amorphous oxide films formed on 316L SS with lower open-circuit potential and higher time value constant [123]. Tuning oxide layer compositions on Co-Cr alloy surfaces with a negative surface charge and hydrophilicity have been proved to reduce platelet adhesion, moderate complement activation, and improved endothelialization [124].

A physicochemical property, surface energy, measured as surface tension determines the stability of molecular bonds at the surface. For a solid surface to be thromboresistant, surface tension should be between 20 and 30 dynes $/ \mathrm{cm}$ [125]. As with the case of most of the metals, interfacial tension is above these values, triggering the biological activities leading to thrombogenesis.

\section{Surface modification of stents}

As discussed in the previous sections, the major complications that have been associated with cardiovascular metal stents are stent thrombosis, restenosis, and ISR, which affect the long-term stability and safety of these materials. Generally, the major obstacles of metal stents are placements during the surgery process, stent thrombosis, and ISR. After implantation of stents, coronary artery infections may rise and lead to potential life critical problems of this percutaneous coronary intervention [25, 126]. Moreover, inflammation due to infection can attack and initiate metal stent restenosis [127]. To address these issues, surface modification is the ultimate process to improve metal stent activity in terms of anti-thrombosis, endothelialization, and anti-restenosis. Hence, in this section, we focused to provide concise information on the different surface modification techniques for cardiovascular metal stents.

The usage of intracoronary stents has continuous challenges that include the inhibition of blood clotting formation and development of restenosis. The interface reactions of biomaterials with the biological environment play a vital role in the biocompatible behavior of the materials. As a result, vast research has been conducted on the development of technologies that optimize the physicochemical surface properties [128, 129]. Over the past few years, there has been increased research interest in studying the surface modification of metal stents to improve the blood contact ability, prevention of coagulation, hyperplasia, and encourage of endothelialization [130]. The most commonly used surface modification techniques include physiochemical treatment, plasma immersion ion implantation (PIII), biological molecules, and drugs [131-133]. 
Prevention of metal stent thrombosis by surface modifications Pure Ti and its alloys are extensively used in the applications of cardiac and cardiovascular due to their inimitable properties. Pure Ti has an attractive hemocompatible characteristic that meets clinical standards, due to the formation of a titanium oxide layer on its surface when under normal conditions [134]. A few studies have proved that the Ti-O layer can prevent thrombosis and improve blood compatibility by surface modification with implantation of phosphorus ions and a subsequent vacuum annealing process, PIII, nanocrystallization of substrates, physical vapor deposition, and chemical vapor deposition [135, 136].

Different materials and techniques have been used to alter the surface of 316L SS with the goal of enhancing its biocompatibility and restricting the release of ions such as molybdenum, chromate, and nickel, which may stimulate the ISR and hyperplasia [137]. The 316L SS surface has been modified by various techniques such as radiofrequency magnetron, electrochemical cyclic voltammetry, and ion implantation to improve the hemocompatibility and avoid the blood clotting [138].

The pure $\mathrm{Fe}$ and $\mathrm{Mg}$ alloys have been used as biodegradable cardiovascular metal stents and with the combination of different alloying elements ( $\mathrm{Co}, \mathrm{W}$, and $\mathrm{S}$ ) can tailor the corrosion resistance and mechanical, biocompatibility properties. The surface of pure $\mathrm{Fe}$ can form a layer of $\mathrm{Fe}-\mathrm{O}$ which helps to enhance the hemocompatibility by PIII and deposition [139]. The Mg alloy surface has been modified by various processes including micro-arc oxidation and plasmaenhanced chemical vapor deposition to obtain the desired properties of blood compatibility and anti-thrombosis [140].

Few drugs act as inhibition agents and may be effectual in anticipation of stent thrombosis. The drug molecules such as aspirin, warfarin, clopidogrel, sirolimus, and thiazolidinediones are used in the form of coatings to stimulate the antithrombosis [141]. The most regularly used drugs to apply during surface modification are the mammalian target of rapamycin and paclitaxel [142].

The usage of biomolecules in surface modification of stents is emerging research in the cardiovascular field. Heparin-, thrombomodulin-, albumin-, aptamers-, phosphorylcholine-, and elastin-inspired polymers are often used biomolecules for better thromboresistance [143]. Several attempts are made to overcome stent thrombogenecity that are comprehensively reviewed [48, 144-146]. The lethal complications associated with stent thrombosis are also governed by the stent design. It has been proved that thin strutted stents exhibited reduced thrombus coverage as compared to thickstrutted ones [147].

Prevention of in-stent restenosis by surface modification In the application of stents for clinical use, the in-stent restenosis (ISR) still exists as a major limitation for wide usage and the development of anti-restenosis for stents is highly demanding in the cardiovascular research area. In recent years, it was found that after implantation of a BMS, the utilization of the probucol and valsartan oral drugs may show the effective in minimization of ISR rate [148, 149].

DES are exhibiting a low rate of restenosis than BMS. In BMS, the ISR takes place at $20-40 \%$ and causes the sudden closure of thrombotic vessels and severe myocardial infarction. Hence, anti-proliferative drug agents have been used to coat on the surface of metal stents to restrict the persistence of in-stent restenosis [150]. Other than drug surface modification, other methods are being developed to improve results. The surface of the stainless steel wafer was exposed to glow discharge plasma with a mixture of $\mathrm{N}_{2} \mathrm{O}$ and $\mathrm{O}_{2}$ to generate the oxynitrites, which stimulate apoptosis to limit ISR and decrease the attachment of platelets [151]. Therefore, the surface modification of metal stents can promote their compatible nature with blood, anti-coagulant, antirestenosis, endothelialization, and biological activities. Prolonged dual antiplatelet therapy (DAPT) is another strategy which makes use of aspirin as well as an ADP receptor inhibitor (thienopyridine) to reduce activation and aggregation of platelets [152]. Even though, the optimal duration of DAPT is still a topic of debate.

\section{Radiopacity}

One of the key aspects during the stenting procedure is the positioning and deployment control of stents by interventional cardiologists with the help of X-ray fluoroscopy. Hunter et al. described radiopacity as the ability of any material to absorb X-rays and to appear white or opaque on radiographs [153]. Radiopacity depends on X-ray attenuation caused by the material of the stent and is characterized by a parameter termed as attenuation coefficient. Attenuation can be defined as the intensity reduction of an X-ray beam as it traverses a material due to absorption or scatter of photons from the beam [154].

When $I_{\text {incident }}$ is the quantity of X-rays incident on a radiographic film and $I_{\text {transmitted }}$ is the transmitted radiation, radiopacity is given by the following equation [155].

Radiopacity $=\frac{I_{\text {incident }}}{I_{\text {transmitted }}}$

An exponential attenuation law was proposed by J. H. Hubbell and S. M. Seltzer for a narrow beam composed of monoenergetic photons transmitted through a material having mass thickness " $x$ " and density " $\rho$ ". [Note. Mass thickness refers to mass per unit area, obtained by multiplying density, $\rho$ with thickness, $t$. 
$\frac{I_{\text {incident }}}{I_{\text {transmitted }}}=\exp [-(\mu / \rho) x]$

In the above expression, $\mu$ is termed as the linear attenuation coefficient $\left(\mathrm{cm}^{-1}\right)$ and the term $\left(\frac{\mu}{\rho}\right)$ is termed as the mass attenuation coefficient $\left(\mathrm{cm}^{2} / \mathrm{g}\right)$. Linear attenuation coefficient can also be used to give an indication of the radiopacity of the metallic stent material. Some of the standardized guidelines followed by device manufacturers to confirm radiopacity are ASTM F640-12, ISO-25539-2, and ISO 6876.

It is very clear that in order to obtain higher radiopacity, the stent material should be composed of elements with higher attenuation coefficients and higher density. Linear attenuation coefficient values of clinically relevant stent materials are calculated and listed in Table 4 with reference to elemental data obtained online from NIST Physical Measurement Laboratory database. Tantalum stents were earlier explored for radiopacity enhancements as they possess a $\mu$ value almost $200 \%$ higher than that of the $316 \mathrm{~L}$ stainless steel. The famous ISAR-STEREO Trial by Kastrati et al. demonstrated that restenosis after a stenting procedure was significantly reduced when using thinner strut devices compared to thicker ones [36]. Henceforth, the challenge was to satisfy the requirements of reduced strut thickness while maintaining adequate radiopacity. However, this requirement posed an issue for tantalum stents, for which formability during stent expansion is difficult owing to a reduced plastic region. Even though 316L SS stents with reduced strut thicknesses were developed, their use was limited owing to reduced visibility. This problem of reduced fluoroscopic visibility was first addressed by the application of radiopaque

Table 4 Calculated values of linear attenuation coefficients for relevant stent materials

\begin{tabular}{ll}
\hline Material & $\begin{array}{l}\text { Linear attenua- } \\
\text { tion coefficient, } \mu \\
{\left[\mathrm{cm}^{-1}\right]}\end{array}$ \\
\hline $316 \mathrm{~L}$ stainless steel & 2.91 \\
MP35N & 3.79 \\
L605 & 7.33 \\
Elgiloy & 3.49 \\
Pt-Cr alloy & 15.51 \\
Pt-Ir alloy & 107.37 \\
Nitinol & 2.58 \\
Ti alloy (Ti-17Ir) & 28.73 \\
Mg alloy (WE43) & 0.32 \\
Armco iron & 2.89 \\
Fe-30Mn & 2.77 \\
Fe-35Mn & 2.75 \\
Zn-Ag alloy & 3.78 \\
\hline
\end{tabular}

surface coatings such as gold which improved traceability and precise positioning of SS stents [156]. Despite these advantages, clinical studies revealed that a gold coating enhanced the risk of restenosis after one year of implantation [157]. Compared to 316L SS stents, cobalt-chromium-based L605 (Co-20Cr-15 W-10Ni-3Fe) stents exhibit enhanced radiopacity owing to the presence of $15 \%$ tungsten which possesses an excellent $\mu$ value of $7.33 \mathrm{~cm}^{-1}$ [158]. Figure $7 \mathrm{a}$ depicts the improved radiopacity of a $\mathrm{CoCr}$ alloy stent which is clearly visible. However, $\mathrm{CoCr}$ stents exhibited recoil problems owing to higher elastic properties compared to stainless steel counterparts [39].

In an attempt to tackle this problem associated with fluoroscopic visibility, platinum with an exceptionally high $\mu$ value of $107.09 \mathrm{~cm}^{-1}$ was alloyed to form a novel class of steel, platinum-enhanced radiopaque stainless steel (PERSS) [52]. Platinum concentration up to $10 \%$ was added to 316LVM stainless steels (UNS S31673) for maintaining the austenitic nature of the alloy. In addition to this, O'Brien et al. tailored a new alloy by adding about $33 \%$ platinum to chromium-rich stainless steel [78] which exhibited improved visibility during clinical procedures. ABI alloy composed mainly of palladium and silver exhibited 2-4 times enhanced radiopacity than 316L stents. Recently developed bioabsorbable Zn-3Ag alloys inserted in porcine iliac arteries demonstrated clearly visible stent dimensions with X-ray visibility diminishing slowly over time and the stent frame was detectable even after 6 months of biodegradation [159]. Figure 7e assists in comparing the lower radiopacity of a magnesium alloy stent compared to a stainless steel stent ascribed to the low density of $\mathrm{Mg}$.

The second strategy to enhance the visibility of coronary arteries is by utilizing radiopaque coatings. O'Brien et al. extensively reviewed on the increasing attention gained by radiopaque coatings for improved visibility and hemocompatibility in the vascular environment [145]. Additionally, radiopacity of a stent can also be enhanced by utilizing radiopaque markers. One of the inherent limitations associated with the polymeric bioabsorbable stent is reduced radiopacity [40]. For the first-in-human fully bioabsorbable DES (poly-L-lactic acid everolimus-eluting), precise location of stent during fluoroscopy was obtained with radiopaque metal markers provided at both ends of the stent [160].

\section{Magnetic susceptibility}

Magnetic resonance (MR) angiography is a well-developed imaging modality which can be efficiently used to visualize the clogged arterial region inside coronary arteries. Coronary MR angiography has several advantages including non-exposure to ionizing radiations, assessment of arteries having heavily calcified plaques, and better visualization of coronary arteries without the aid of exogenous contrast 

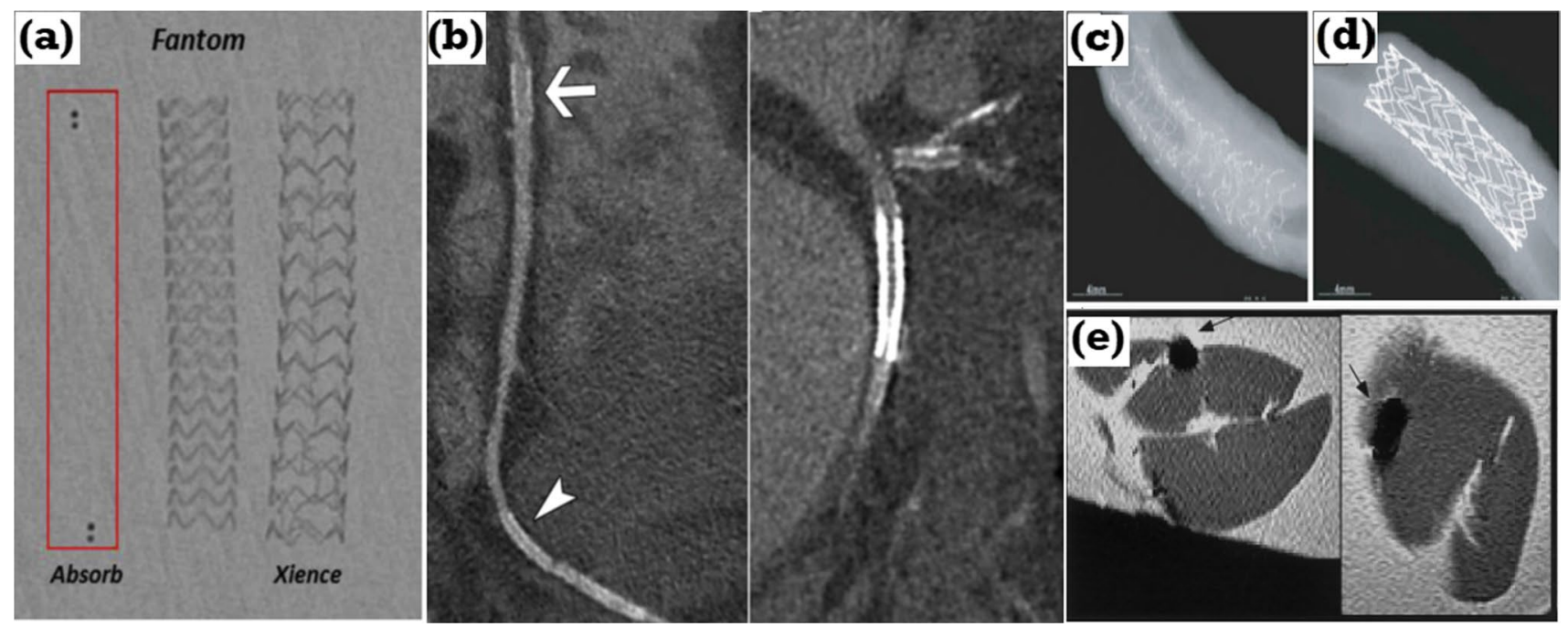

Fig. 7 (a) Radiopacity comparison of Fantom (iodinated polycarbonate copolymer of tyrosine), Absorb (polylactic acid), and Xience (L605 Co-Cr) stents [166]. (b) Artefact generation in implanted stents showing metallic artefacts with varying materials and designs of the

agents [161]. However, the widespread use of MR imaging for coronary metallic stents is being hampered by the formation of image artefacts which are defined as those pixels which do not faithfully represent the tissue components under examination $[162,163]$.

One of the predominant sources of this signal attenuation from a materials perspective is the difference in magnetic susceptibility of the implanted stent material and the surrounding tissues. Volume magnetic susceptibility $\left(\chi_{\mathrm{vol}}\right)$ is a parameter that explains how "susceptible" a material is to get temporarily magnetized when subjected to an external magnetic field and is defined as magnetization $(M)$ produced per unit magnetic field strength $(H)$ [164].

$\chi_{\mathrm{vol}}=\frac{M}{H}$

Magnetic susceptibility can also be expressed in terms of mass magnetic susceptibility (unit $\mathrm{m}^{3} / \mathrm{kg}$ ), obtained by dividing the volume magnetic susceptibility value by the density of the material [165]. Generally, diamagnetic materials are associated with weak negative susceptibility values as they have no permanent net magnetic moment per atom and they oppose applied magnetic field (e.g., $\mathrm{Cu}, \mathrm{Ag}, \mathrm{Au}$ ). In the case of paramagnetic substances, small positive magnetic susceptibility is developed, due to the presence of net magnetic atomic moments owing to the existence of unpaired electrons in partially filled orbits and realignment of electron paths when exposed to external magnetic fields (e.g., $\mathrm{Mg}, \mathrm{Mo}, \mathrm{Li}, \mathrm{Ta}$ ), whereas a large positive susceptibility is exhibited by ferromagnetic materials which get easily magnetized by a moderately applied magnetic field due to the stent [167]. (c) X-ray photographs proving poor radiopacity of a magnesium alloy stent compared to a radiopaque (d) stainless steel stent [168]. (e) Dark region shows artefacts generated in an MR image of a stent implanted inside a pig's heart [169]

realignment of individual magnetic domains inside the material (e.g., $\mathrm{Fe}, \mathrm{Ni}, \mathrm{Co}$ ). Thus, 316L SS and cobalt-based stents have higher magnetic susceptibility as being ferromagnetic. That being the case, signal attenuation occurs while imaging high magnetic susceptible ferromagnetic metallic stents and lower diamagnetic human tissues $\left(-11 \times 10^{-6}\right.$ to $\left.-7 \times 10^{-6}\right)$, affecting exact diagnosis. Magnetic susceptibility values of some relevant materials for stent application are summarized in Table 5. A quantitative evaluation of artefact generation using a 3D artefact rendering method was performed with materials like $\mathrm{SS}, \mathrm{Co}-\mathrm{Cr}$ alloy, $\mathrm{Nb}, \mathrm{Zr}, \mathrm{Ti}, \mathrm{Mo}, \mathrm{Al}, \mathrm{Sn}, \mathrm{Cu}$, and $\mathrm{Ag}$. Artefact generation is clearly visible in the case of $\mathrm{SS}$ and Co-Cr alloy. Additionally, specimen direction and imaging conditions are found to significantly affect the artefact generation as evidenced in Fig. $7 \mathrm{~b}$ and $\mathrm{d}$.

A number of works are identified related to the development of niobium-based alloys for MRI compatible stents. O'Brien et al. developed a niobium-based alloy, $\mathrm{Nb}-28 \mathrm{Ta}-3.5 \mathrm{~W}-1.3 \mathrm{Zr}$, which could be practically applied for coronary stent applications [61]. In total, 28\% tantalum was selected for alloying, based on the fact that it provides solid solution strengthening, along with reduced magnetic susceptibility. Moreover, tungsten content was reduced from 10 to $3.5 \mathrm{wt} \%$, owing to the fabrication challenges due to reduced ductility. Initial magnetic susceptibility studies were in the desired lower region which might be due to the meager susceptibility values of individual elements. Besides, experimental measurement of artefact sizes for this niobium alloy demonstrated lower magnetic field disruption compared to that of stainless steels [80]. This material developed uniform artefacts, shorter with small diameter and not affecting 
Table 5 Magnetic susceptibility values of pertinent materials for stents [164]

\begin{tabular}{ll}
\hline Material & $\begin{array}{l}\text { Magnetic sus- } \\
\text { ceptibility value } \\
{\left[\times 10^{-6}\right]}\end{array}$ \\
\hline Stainless steel [austenitic] & $3520-6700$ \\
Palladium & 806 \\
Nickel & 600 \\
Vanadium & 384 \\
Chromium & 320 \\
Platinum & 279 \\
Cobalt & 250 \\
Nitinol & 245 \\
Niobium & 237 \\
Titanium & 182 \\
Tantalum & 178 \\
Molybdenum & 123 \\
Zirconium & 109 \\
Tungsten & 77.2 \\
Iridium & 25 \\
Magnesium & 11.7 \\
Zinc & -15.7 \\
Human tissues & -11 to -7 \\
\hline &
\end{tabular}

the center of the stent lumen. It was also pointed out that larger artefacts were generated when stents were oriented perpendicular to the applied magnetic field. These alloys also exhibited enhanced corrosion resistance attributed to the presence of surface layer composed of niobium oxide and tantalum oxide. Another niobium alloy, $\mathrm{Nb}-60 \mathrm{Ta}-2 \mathrm{Zr}$, already discussed above exhibited a magnetic susceptibility of $214 \times 10^{-6}$, about $3 \%$ of that about $316 \mathrm{~L}$ stainless steel [170]. Increasing the tantalum content, reduced the susceptibility of the alloy, along with an improved yield strength and reduced ductility. Similar to the previous reports, low susceptibility values were found to be inherently influenced by the individual element susceptibility and concentration.

MRI of Pt-Ir electrodes resulted in artefacts which increased the apparent diameter of electrodes due to paramagnetic nature of Pt-Ir [171]. Another precious metal alloy, ABI alloy, exhibited reduced MRI artefact due to the lower magnetic susceptibility values associated silver and palladium. MRI compatibility of the ABI alloy, measured by using different gradient echo techniques, developed fewer artefacts during MR imaging; however, some signal intensity decrease was noticed owing to the Faraday cage effect.

Zirconium-based alloys are also potential candidates owing to their lower magnetic susceptibility, biocompatibility, and corrosion resistance. Li et al. developed MRI compatible zirconium-ruthenium alloys and the results indicated that $1 \%$ ruthenium addition gave rise to ultralow magnetic susceptibility, one-sixth to that of conventional $\mathrm{Co}-\mathrm{Cr}$ alloys [172]. M-H curves of $\mathrm{Zr}-\mathrm{Ru}$ alloy obtained using a magnetometer at room temperature exhibited linear variation relationship. Most recently, Guo et al. reported a magnetic susceptibility of $1.42 \times 10^{-6}$ in a metastable beta-type $\mathrm{Zr}-12 \mathrm{Nb}-4 \mathrm{Sn}$ alloy [173]. Moreover, quantitative determination of the magnetic force exerted on a stent in MRI magnet is also significant as large susceptibility of stent material, higher magnetic field, and larger gradient can increase the magnetic force on metallic implant upon entering an MRI magnet [174].

\section{Future outlook}

Stent technologies have been continuously evolving for more than 30 years. Several clinical trials have been reported to compare the long-term risks and benefits associated with the widely used BMS and second-generation DES. Even though the rate of repeat revascularization is lower for DES compared to BMS, no significant difference in death rates and myocardial infarction in patients receiving DES and BMS was reported [17]. Current DES technologies aim to develop innovative bioabsorbable polymer coatings which can perform the functionality of optimal drug release without any undesirable inflammatory phenomena. Moreover, the development of drugs or combination of current drugs such as everolimus, zotarolimus, umirolimus, novolimus, and amphilimus can improve the clinical efficiency of DES. Another emerging concept is the polymer-free DES which makes use of drug reservoirs such as micro/nanopores or drug-coated stents. For clinical situations demanding BMS, stents with ultrathin strut thickness as well as improved radiopacity without ISR should be researched. Novel alloy systems such as high entropy alloy and bulk metallic glasses and promising material processing routes such as additive manufacturing open new windows for enabling further advancements in rapid exploration and development of newer generation of stent platforms.

With continuous improvement in material technologies, emerging bioactive coatings, and new drug combinations, bioabsorbable stents will be the future game-changer holding potential for complete vascular physiology restoration after stent resorption. The application of finite element methods can assist in simulating newer designs which can provide radial support to ensure effective support during the biodegradation period. Systematic exploration of functional properties of neoendothelium (of re-endothelialized stented arteries) poses a new challenge for researchers [175]. The role of microRNAs in mediating cell signaling between endothelial cells, smooth muscle cells, and platelets can increase our knowledge on the basis of ISR and stent thrombosis phenomena [176]. Moreover, microRNAs can serve as potential 
biomarkers due to the fact that their concentration levels in flowing bloodstream change in the case of a vascular injury. Evolving research will assist in refining the optimal duration of dual antiplatelet therapy durations and developing novel antiplatelet agents with lower bleeding risks and risk factors of recurrent ischemia.

Integrating sensors based on MEMS technology with stent design can ameliorate the ISR detection by sensing the change in blood flow parameters (velocity, pressure, shear stress) and undesirable cell growth [177]. Even though this field represents the next evolution of stent technology, the integration of sensor, stent, and the wireless communication system still remains as a limiting factor. Internet of Things (IOT) is another prospective field that can aid in constant patient monitoring and can store large volume of specific medical data in order to establish trends and future health prediction [177]. Robot-assisted percutaneous coronary interventions hold potential in terms of improved procedural quality and outcomes providing improved accuracy. Such a system can be particularly advantageous to assist in target vessel revascularization with precise and repeatable tool motion and to allow interventional cardiologists to perform off-site procedures thereby improving the global access $[178,179]$.

Technical advancements in the field of MRI hardware, software, and advanced acquisition technologies are increasing and have led to rapid image acquisition as well as improved image quality. The next big leap in the field of MRI will be the development and dissemination of highperformance, low-field strength MRI systems [180]. Emerging techniques such as 4D flow magnetic resonance imaging and patient-specific computational fluid dynamics can provide more insights into the vessel wall shear stress, 3D velocity vector fields, or a combined velocity and pressure fields near to stented regions. In addition, 3D intravascular optical coherence tomography (3D-OCT) can be helpful to conclusively diagnose stent fracture, uncovered lesion region, and incomplete stent apposition resulting in better clinical outcomes.

\section{Conclusions}

A wide variety of innovations and improvements are being continuously made in the development of coronary stent materials. However, a concurrent approach is highly imperative for improving the clinical efficiency of cardiovascular stent materials. A clear need still exists for analyzing mechanical properties, particularly fatigue as well as corrosion fatigue data of bioabsorbable stents during stent design process. The complex cascade of blood coagulation events is enigmatic and a clear understanding is yet to be established to eradicate the stent thrombosis. In addition to the bulk properties, surface characteristics are pertinent for developing a novel stent material with meager thrombotic events. Moreover, a conspicuous consideration should be given to enhanced visibility and reduced magnetic artefacts for an efficient percutaneous interventional procedure. The evidence summarized in the present review serves as a framework for clinicians, biomaterial scientists, engineers, and interventional cardiologists across the globe to design innovative stent technologies in order to eradicate the global burden of coronary artery disease.

Funding JV would like to acknowledge the funding received from Council of Scientific and Industrial Research (CSIR), India, under Direct-SRF scheme (Award No.: 09/844(0108)/2020-EMR-I).

Data availability statement The datasets generated during and/or analyzed during the current study are available from the corresponding author on reasonable request.

\section{Declarations}

Conflict of interest The authors declare no competing interests.

\section{References}

1. World Health Organization. World Health Statistics 2016: monitoring health for the SDGs, 2016. http://www.who.int/ gho/publications/world_health_statistics/2016/en/. Accessed 4 Apr 2020.

2. Benjamin Emelia J, Muntner P, Alonso A, Bittencourt Marcio S, Callaway Clifton W, Carson April P, Chamberlain Alanna M, Chang Alexander R, Cheng S, Das Sandeep R, Delling Francesca N, Djousse L, Elkind Mitchell SV, Ferguson Jane F, Fornage M, Jordan Lori C, Khan Sadiya S, Kissela Brett M, Knutson Kristen L, Kwan Tak W, Lackland Daniel T, Lewis Tené T, Lichtman Judith H, Longenecker Chris T, Loop Matthew S, Lutsey Pamela L, Martin Seth S, Matsushita K, Moran Andrew E, Mussolino Michael E, O'Flaherty M, Pandey A, Perak Amanda M, Rosamond Wayne D, Roth Gregory A, Sampson Uchechukwu KA, Satou Gary M, Schroeder Emily B, Shah Svati H, Spartano Nicole L, Stokes A, Tirschwell David L, Tsao Connie W, Turakhia Mintu P, VanWagner Lisa B, Wilkins John T, Wong Sally S, Virani Salim S. Heart disease and stroke statistics-2019 update: a report from the American Heart Association. Circulation. 2019;139(10): e56-528.

3. Gruentzig AR, Meier B. Percutaneous transluminal coronary angioplasty. The first five years and the future. Int J Cardiol. 1983;2(3):319-23.

4. Lincoff AM, Popma JJ, Ellis SG, Hacker JA, Topol EJ. Abrupt vessel closure complicating coronary angioplasty: clinical, angiographic and therapeutic profile. J Am Coll Cardiol. 1992;19(5):926-35.

5. Sigwart U. The stent story: how it all started.... Eur Heart J. 2017;38(28):2171-2.

6. Stoeckel D, Pelton A, Duerig T. Self-expanding nitinol stents: material and design considerations. Eur Radiol. 2004;14(2):292-301.

7. Zidar DA. Newer-generation drug-eluting stents: heal thyself. Sci Transl Med. 2013;5(211):211ec190. 
8. Ong ATL, Serruys PW. Technology Insight: an overview of research in drug-eluting stents. Nat Clin Pract Cardiovasc Med. 2005;2(12):647-58.

9. Hermawan H, Dubé D, Mantovani D. Developments in metallic biodegradable stents. Acta Biomater. 2010;6(5):1693-7.

10. Hermawan H, Purnama A, Dube D, Couet J, Mantovani D. FeMn alloys for metallic biodegradable stents: degradation and cell viability studies. Acta Biomater. 2010;6(5):1852-60.

11. Bowen PK, Shearier ER, Zhao S, Guillory Ii RJ, Zhao F, Goldman J, Drelich JW. Biodegradable metals for cardiovascular stents: from clinical concerns to recent $\mathrm{Zn}$-alloys. Adv Healthc Mater. 2016;5(10):1121-40.

12. Bangalore $\mathrm{S}$. The elusive late benefit of biodegradable polymer drug-eluting stents. Circulation. 2019;139(3):334-6.

13. Hassan AKM, Bergheanu SC, Stijnen T, van der Hoeven BL, Snoep JD, Plevier JWM, Schalij MJ, Wouter Jukema J. Late stent malapposition risk is higher after drug-eluting stent compared with bare-metal stent implantation and associates with late stent thrombosis. Eur Heart J. 2009;31(10):1172-80.

14. Gunn J, Cumberland D. Does stent design influence restenosis? Eur Heart J. 1999;20(14):1009-13.

15. Baumann F, Fust J, Peter Engelberger R, Hügel U, Do D-D, Willenberg T, Baumgartner I, Diehm N. Early recoil after balloon angioplasty of tibial artery obstructions in patients with critical limb ischemia. J Endovasc Ther. 2014;21(1):44-51.

16. Bi Y, Wu T, Jiang X, Kislauskis E, Laham R. Abstract 16528: Structural instability, the potential cause for current BVS scaffold's failure. Circulation. 2018;138(Suppl_1):A16528.

17. Bønaa KH, Mannsverk J, Wiseth R, Aaberge L, Myreng Y, Nygård O, Nilsen DW, Kløw N-E, Uchto M, Trovik T, Bendz B, Stavnes S, Bjørnerheim R, Larsen A-I, Slette M, Steigen T, Jakobsen OJ, Bleie Ø, Fossum E, Hanssen TA, Dahl-Eriksen Ø, Njølstad I, Rasmussen K, Wilsgaard T, Nordrehaug JE. Drugeluting or bare-metal stents for coronary artery disease. N Engl J Med. 2016;375(13):1242-52.

18. Meier B. Interventional cardiology, where real life and science do not necessarily meet $\dagger$. Eur Heart J. 2016;37(26):2014-9.

19. Torii S, Jinnouchi H, Sakamoto A, Kutyna M, Cornelissen A, Kuntz S, Guo L, Mori H, Harari E, Paek KH, Fernandez R, Chahal D, Romero ME, Kolodgie FD, Gupta A, Virmani R, Finn AV. Drug-eluting coronary stents: insights from preclinical and pathology studies. Nat Rev Cardiol. 2020;17(1):37-51.

20. Lee D-H, de la Torre Hernandez JM. The newest generation of drug-eluting stents and beyond. Eur Cardiol. 2018;13(1):54-9.

21. McMahon S, Bertollo N, Cearbhaill EDO, Salber J, Pierucci L, Duffy P, Dürig T, Bi V, Wang W. Bio-resorbable polymer stents: a review of material progress and prospects. Prog Polym Sci. 2018;83:79-96.

22. Zhang L-C, Chen L-Y. A review on biomedical titanium alloys: recent progress and prospect. Adv Eng Mater. 2019;21(4):1801215.

23. Moher D, Liberati A, Tetzlaff J, Altman DG. Preferred Reporting Items for Systematic Reviews and Meta-Analyses: the PRISMA statement. Ann Intern Med. 2009;151(4):264-9 W64.

24. Liberati A, Altman DG, Tetzlaff J, Mulrow C, Gøtzsche PC, Ioannidis JPA, Clarke M, Devereaux PJ, Kleijnen J, Moher D. The PRISMA statement for reporting systematic reviews and meta-analyses of studies that evaluate healthcare interventions: explanation and elaboration. BMJ. 2009;339:b2700.

25. Torrado J, Buckley L, Durán A, Trujillo P, Toldo S, Valle Raleigh J, Abbate A, Biondi-Zoccai G, Guzmán LA. Restenosis, stent thrombosis, and bleeding complications: navigating between Scylla and Charybdis. J Am Coll Cardiol. 2018;71(15):1676-95.

26. Vishnu J, Manivasagam G. Perspectives on smart stents with sensors: from conventional permanent to novel bioabsorbable smart stent technologies. Med Devices Sensors. 2020;3(6):e10116.
27. Kan J, Ge Z, Zhang J-J, Liu Z-Z, Tian N-L, Ye F, Li S-J, Qian X-S, Yang S, Chen M-X, Rab T, Chen S-L. Incidence and clinical outcomes of stent fractures on the basis of 6,555 patients and 16,482 drug-eluting stents from 4 centers. JACC: Cardiovasc Interv. 2016;9(11):1115.

28. Chhatriwalla AK, Cam A, Unzek S, Bhatt DL, Raymond RE, Lincoff AM, Whitlow PL, Ellis SG, Tuzcu EM, Kapadia SR. Drug-eluting stent fracture and acute coronary syndrome. Cardiovasc Revasc Med. 2009;10(3):166-71.

29. Kosonen P, Vikman S, Jensen LO, Lassen JF, Harnek J, Olivecrona GK, Erglis A, Fossum E, Niemela M, Kervinen K, Ylitalo A, Pietila M, Aaroe J, Kellerth T, Saunamaki K, Thayssen P, Hellsten L, Thuesen L, Niemela K. Intravascular ultrasound assessed incomplete stent apposition and stent fracture in stent thrombosis after bare metal versus drug-eluting stent treatment the Nordic Intravascular Ultrasound Study (NIVUS). Int J Cardiol. 2013;168(2):1010-6.

30. Schillinger M, Minar E. Endovascular stent implantation for treatment of peripheral artery disease. Eur J Clin Invest. 2007;37(3):165-70

31. Yin T-Y, Wang G-X, Zhang D-C, Du D-Y, Li Z-G, Luo L-L, Hou Y-B, Wang Y-Z, Zhao J-B. Endothelialization and instent restenosis on the surface of glycoprotein IIIa monoclonal antibody eluting stent. J Biomed Mater Res, Part A. 2012;100A(6):1398-406.

32. McFadden EP, Stabile E, Regar E, Cheneau E, Ong AT, Kinnaird T, Suddath WO, Weissman NJ, Torguson R, Kent KM, Pichard AD, Satler LF, Waksman R, Serruys PW. Late thrombosis in drug-eluting coronary stents after discontinuation of antiplatelet therapy. Lancet. 2004;364(9444):1519-21.

33. Pfisterer M, Brunner-La Rocca HP, Buser PT, Rickenbacher P, Hunziker P, Mueller C, Jeger R, Bader F, Osswald S, Kaiser C. Late clinical events after clopidogrel discontinuation may limit the benefit of drug-eluting stents: an observational study of drug-eluting versus bare-metal stents. J Am Coll Cardiol. 2006;48(12):2584-91.

34. Cook S, Wenaweser P, Togni M, Billinger M, Morger C, Seiler $\mathrm{C}$, Vogel R, Hess O, Meier B, Windecker S. Incomplete stent apposition and very late stent thrombosis after drug-eluting stent implantation. Circulation. 2007;115(18):2426-34.

35. Philip F, Stewart S, Southard JA. Very late stent thrombosis with second generation drug eluting stents compared to bare metal stents: network meta-analysis of randomized primary percutaneous coronary intervention trials. Catheter Cardiovasc Interv. 2016;88(1):38-48.

36. Kastrati A, Mehilli J, Dirschinger J, Dotzer F, Schuhlen H, Neumann FJ, Fleckenstein M, Pfafferott C, Seyfarth M, Schomig A. Intracoronary stenting and angiographic results: strut thickness effect on restenosis outcome (ISAR-STEREO) trial. Circulation. 2001;103(23):2816-21.

37. Pache J, Kastrati A, Mehilli J, Schuhlen H, Dotzer F, Hausleiter J, Fleckenstein M, Neumann FJ, Sattelberger U, Schmitt C, Muller $\mathrm{M}$, Dirschinger J, Schomig A. Intracoronary stenting and angiographic results: strut thickness effect on restenosis outcome (ISAR-STEREO-2) trial. J Am Coll Cardiol. 2003;41(8):1283-8.

38. Choudhry S, Balzer D, Murphy J, Nicolas R, Shahanavaz S. Percutaneous carotid artery access in infants $<3$ months of age. Catheter Cardiovasc Interv. 2016;87(4):757-61.

39. Menown IB, Noad R, Garcia EJ, Meredith I. The platinum chromium element stent platform: from alloy, to design, to clinical practice. Adv Ther. 2010;27(3):129-41.

40. Attia MF, Brummel BR, Lex TR, Van Horn BA, Whitehead DC, Alexis F. Recent advances in polyesters for biomedical imaging. Adv Healthcare Mater. 2018;7(22):1800798.

41. Groover MP. Fundamentals of modern manufacturing: materials, processes, and systems. Wiley; 2010. 
42. Clifford M, Simmons K, Shipway P. An introduction to mechanical engineering: Part 1. CRC Press; 2009.

43. Agrawal M, Hakeem A, Ahmed Z, Uretsky BF. Classification of mechanisms of strut malapposition after angiographically optimized stent implantation: an optical coherence tomography study. Catheter Cardiovasc Interv. 2017;90(2):225-32.

44. Mizuki T, Kubo T, Horimoto K, Matsusaka H, Ashihara T. Successful retrieval of an entrapped coronary stent with its delivery system by small balloon dilatation at the entrapped site: a case report. J Indian Coll Cardiol. 2015;5(1):67-70.

45. Ling AJ, Mwipatayi P, Gandhi T, Sieunarine K. Stenting for carotid artery stenosis: fractures, proposed etiology and the need for surveillance. J Vasc Surg. 2008;47(6):1220-6.

46. Halwani DO, Anderson PG, Brott BC, Anayiotos AS, Lemons JE. Clinical device-related article surface characterization of explanted endovascular stents: evidence of in vivo corrosion, Journal of biomedical materials research. Part B, Applied biomaterials. 2010;95(1):225-38.

47. Foin N, Alegria E, Sen S, Petraco R, Nijjer S, Di Mario C, Francis DP, Davies JE. Importance of knowing stent design threshold diameters and post-dilatation capacities to optimise stent selection and prevent stent overexpansion/incomplete apposition during PCI. Int J Cardiol. 2013;166(3):755-8.

48. Mani G, Feldman MD, Patel D, Agrawal CM. Coronary stents: a materials perspective. Biomaterials. 2007;28(9):1689-710.

49. Lévesque J, Dubé D, Fiset M, Mantovani D. Materials and properties for coronary stents. Advanced Materials and Processes. 2004;162(9):45-48.

50. Maglione J, Bergersen L, Lock James E, McElhinney Doff B. Ultra-high-pressure balloon angioplasty for treatment of resistant stenoses within or adjacent to previously implanted pulmonary arterial stents. Circulation: Cardiovasc Interv. 2009;2(1):52-8.

51. Khalilimeybodi A, Alishzadeh Khoei A, Sharif-Kashani B. Future balloon-expandable stents: high or low-strength materials? Cardiovasc Eng Technol. 2020;11(2):188-204.

52. Craig CH, Friend CM, Edwards MR, Cornish LA, Gokcen NA. Mechanical properties and microstructure of platinum enhanced radiopaque stainless steel (PERSS) alloys. J Alloy Compd. 2003;361(1):187-99.

53. Köster R, Vieluf D, Kiehn M, Sommerauer M, Kähler J, Baldus S, Meinertz T, Hamm CW. Nickel and molybdenum contact allergies in patients with coronary in-stent restenosis. The Lancet. 2000;356(9245):1895-7.

54. Li J, Yang Y, Ren Y, Dong J, Yang K. Effect of cold deformation on corrosion fatigue behavior of nickel-free high nitrogen austenitic stainless steel for coronary stent application. J Mater Sci Technol. 2018;34(4):660-5.

55. Katada Y, Taguchi T. Nickel-Free High-Nitrogen Stainless Steel. In: Niinomi M, Narushima T, Nakai M, editors. Advances in metallic biomaterials: tissues, materials and biological reactions. Berlin, Heidelberg: Springer, Berlin Heidelberg; 2015. p. 125-56.

56. Bangalore S, Toklu B, Patel N, Feit F, Stone Gregg W. Newergeneration ultrathin strut drug-eluting stents versus older secondgeneration thicker strut drug-eluting stents for coronary artery disease. Circulation. 2018;138(20):2216-26.

57. van Bommel RJ, Lemmert ME, van Mieghem NM, van Geuns R-J, van Domburg RT, Daemen J. Occurrence and predictors of acute stent recoil-a comparison between the xience prime cobalt chromium stent and the promus premier platinum chromium stent. Catheter Cardiovasc Interv. 2018;91(3):E21-8.

58. Ringel RE, Gauvreau K, Moses H, Jenkins KJ. Coarctation of the Aorta Stent Trial (COAST): study design and rationale. Am Heart J. 2012;164(1):7-13.

59. Ewert P, Schubert S, Peters B, Abdul-Khaliq H, Nagdyman N, Lange PE. The CP stent-short, long, covered-for the treatment of aortic coarctation, stenosis of pulmonary arteries and caval veins, and Fontan anastomosis in children and adults: an evaluation of 60 stents in 53 patients. Heart. 2005;91(7):948-53.

60. Zheng Y, Xu X, Xu Z, Wang J, Cai H. Introduction of the biofunctions into traditional metallic biomaterials. In: Zheng Y, Xu X, Xu Z, Wang J, Cai H, editors. Metallic biomaterials. 2017. p. $31-57$.

61. O'Brien B, Stinson J, Carroll W. Development of a new niobiumbased alloy for vascular stent applications. J Mech Behav Biomed Mater. 2008;1(4):303-12.

62. Li HZ, Xu J. MRI compatible Nb-Ta-Zr alloys used for vascular stents: optimization for mechanical properties. J Mech Behav Biomed Mater. 2014;32:166-76.

63. Geetha M, Singh AK, Asokamani R, Gogia AK. Ti based biomaterials, the ultimate choice for orthopaedic implants - a review. Prog Mater Sci. 2009;54(3):397-425.

64. Aljihmani L, Alic L, Boudjemline Y, Hijazi ZM, Mansoor B, Serpedin E, Qaraqe K. Magnesium-based bioresorbable stent materials: review of reviews. J Bio- Tribo-Corros. 2019;5(1):26.

65. O'Brien B, Stinson J, Carroll W. Initial exploration of Ti-Ta, TiTa-Ir and Ti-Ir alloys: candidate materials for coronary stents. Acta Biomater. 2008;4(5):1553-9.

66. Prima F, Sun F, Vermaut P, Gloriant T, Mantovani D, Jacques PJ. High performance beta titanium alloys as a new material perspective for cardiovascular applications. Mater Sci Forum. 2012;706-709:578-83.

67. Gordin DM, Sun F, Laillé D, Prima F, Gloriant T. How a new strain transformable titanium-based biomedical alloy can be designed for balloon expendable stents. Materialia. 2020;10:100638.

68. Bowen PK, Drelich A, Drelich J, Goldman J. Rates of in vivo (arterial) and in vitro biocorrosion for pure magnesium. J Biomed Mater Res, Part A. 2015;103(1):341-9.

69. Peuster M, Hesse C, Schloo T, Fink C, Beerbaum P, von Schnakenburg C. Long-term biocompatibility of a corrodible peripheral iron stent in the porcine descending aorta. Biomaterials. 2006;27(28):4955-62.

70. Jaishankar M, Tseten T, Anbalagan N, Mathew BB, Beeregowda $\mathrm{KN}$. Toxicity, mechanism and health effects of some heavy metals. Interdiscip Toxicol. 2014;7(2):60-72.

71. Bowen PK, Drelich J, Goldman J. Zinc exhibits ideal physiological corrosion behavior for bioabsorbable stents. Adv Mater. 2013;25(18):2577-82.

72. Bukala J, Kwiatkowski P, Malachowski J. Numerical analysis of crimping and inflation process of balloon-expandable coronary stent using implicit solution. Int J Numer Methods Biomed Eng. 2017;33(12):e2890.

73. Martin D, Boyle FJ. Computational structural modelling of coronary stent deployment: a review. Comput Methods Biomech Biomed Engin. 2011;14(4):331-48.

74. Bukala J, Kwiatkowski P, Malachowski J. Numerical analysis of stent expansion process in coronary artery stenosis with the use of non-compliant balloon. Biocybern Biomed Eng. 2016;36(1):145-56.

75. Moravej M, Mantovani D. Biodegradable metals for cardiovascular stent application: interests and new opportunities. Int J Mol Sci. 2011;12(7):4250-70.

76. Yang K, Ren Y. Nickel-free austenitic stainless steels for medical applications. Sci Technol Adv Mater. 2010;11(1):014105.

77. Poncin P, Millet C, Chevy J, Proft J. Comparing and optimizing Co-Cr tubing for stent applications, Medical Device Materials II - Proceedings of the Materials and Processes for Medical Devices Conference 2004. 2005.

78. O'Brien BJ, Stinson JS, Larsen SR, Eppihimer MJ, Carroll WM. A platinum-chromium steel for cardiovascular stents. Biomaterials. 2010;31(14):3755-61. 
79. Al-Mangour B. Coronary stents fracture: an engineering approach (review). Mater Sci Appl. 2013;04(10):606-21.

80. O'Brien BJ, Stinson JS, Boismier DA, Carroll WM. Characterization of an NbTaWZr alloy designed for magnetic resonance angiography compatible stents. Biomaterials. 2008;29(34):4540-5.

81. Li H-Z, Xu J. MRI compatible $\mathrm{Nb}-\mathrm{Ta}-\mathrm{Zr}$ alloys used for vascular stents: optimization for mechanical properties. J Mech Behav Biomed Mater. 2014;32:166-76.

82. O'Brien B, Stinson J, Carroll W. Initial exploration of Ti-Ta, TiTa-Ir and Ti-Ir alloys: candidate materials for coronary stents. Acta Biomater. 2008;4(5):1553-9.

83. Niu J, Tang Z, Huang H, Pei J, Zhang H, Yuan G, Ding W. Research on a $\mathrm{Zn}-\mathrm{Cu}$ alloy as a biodegradable material for potential vascular stents application. Mater Sci Eng, C. 2016;69:407-13.

84. Katarivas Levy G, Goldman J, Aghion E. The prospects of zinc as a structural material for biodegradable implants-a review paper. Metals. 2017;7(10):402.

85. Halwani DO, Anderson PG, Brott BC, Anayiotos AS, Lemons JE. The role of vascular calcification in inducing fatigue and fracture of coronary stents, Journal of biomedical materials research. Part B, Applied biomaterials. 2012;100(1):292-304.

86. Kaushish JP. Manufacturing processes. PHI Learning; 2010.

87. Sweeney CA, O'Brien B, Dunne FPE, McHugh PE, Leen SB. Micro-scale testing and micromechanical modelling for high cycle fatigue of $\mathrm{CoCr}$ stent material. J Mech Behav Biomed Mater. 2015;46:244-60.

88. Sweeney CA, O'Brien B, McHugh PE, Leen SB. Experimental characterisation for micromechanical modelling of $\mathrm{CoCr}$ stent fatigue. Biomaterials. 2014;35(1):36-48.

89. Sweeney CA, O'Brien B, Dunne FPE, McHugh PE, Leen SB. Strain-gradient modelling of grain size effects on fatigue of $\mathrm{CoCr}$ alloy. Acta Mater. 2014;78:341-53.

90. Khatibi G, Lederer M, Betzwar Kotas A, Frotscher M, Krause A, Poehlmann S. High-cycle fatigue behavior of thin-walled $\mathrm{CoCr}$ tubes. Int J Fatigue. 2015;80:103-12.

91. Azaouzi M, Makradi A, Petit J, Belouettar S, Polit O. On the numerical investigation of cardiovascular balloon-expandable stent using finite element method. Comput Mater Sci. 2013;79:326-35.

92. Kapnisis K, Constantinides G, Georgiou H, Cristea D, Gabor C, Munteanu D, Brott B, Anderson P, Lemons J, Anayiotos A. Multi-scale mechanical investigation of stainless steel and cobaltchromium stents. J Mech Behav Biomed Mater. 2014;40:240-51.

93. Li J, Luo Q, Xie Z, Li Y, Zeng Y. Fatigue life analysis and experimental verification of coronary stent. Heart Vessels. 2010;25(4):333-7.

94. Gu XN, Zhou WR, Zheng YF, Cheng Y, Wei SC, Zhong SP, $\mathrm{Xi}$ TF, Chen LJ. Corrosion fatigue behaviors of two biomedical Mg alloys - AZ91D and WE43 - in simulated body fluid. Acta Biomater. 2010;6(12):4605-13.

95. Hermawan $\mathrm{H}$. Updates on the research and development of absorbable metals for biomedical applications. Prog Biomater. 2018;7(2):93-110

96. Xie D, Leng YX, Jing FJ, Huang N. A brief review of biotribology in cardiovascular devices. Biosurf Biotribol. 2015;1(4):249-62.

97. Jaffer IH, Fredenburgh JC, Hirsh J, Weitz JI. Medical deviceinduced thrombosis: what causes it and how can we prevent it? J Thromb Haemost. 2015;13(S1):S72-81.

98. Mackman N. Triggers, targets and treatments for thrombosis. Nature. 2008;451(7181):914-8.

99. Varga-Szabo D, Pleines I, Nieswandt B. Cell adhesion mechanisms in platelets. Arterioscler Thromb Vasc Biol. 2008;28(3):403-12.
100. Reininger AJ. Function of von Willebrand factor in haemostasis and thrombosis. Haemophilia. 2008;14(s5):11-26.

101. Ruggeri ZM. Platelets in atherothrombosis. Nat Med. 2002;8(11):1227-34.

102. Bartlet K, Movafaghi S, Kota A, Popat KC. Superhemophobic titania nanotube array surfaces for blood contacting medical devices. RSC Adv. 2017;7(56):35466-76.

103. Kafkas N, Dragasis S. Current knowledge on very late stent thrombosis. Cont Cardiol Educ. 2018;4(1):40-4.

104. Varenhorst C, Lindholm M, Sarno G, Olivecrona G, Jensen U, Nilsson J, Carlsson J, James S, Lagerqvist B. Stent thrombosis rates the first year and beyond with new- and old-generation drug-eluting stents compared to bare metal stents. Clin Res Cardiol. 2018;107(9):816-23.

105. Claessen BE, Henriques JPS, Jaffer FA, Mehran R, Piek JJ, Dangas GD. Stent thrombosis: a clinical perspective. JACC: Cardiovasc Interv. 2014;7(10):1081-92.

106. Seyfert UT, Biehl V, Schenk J. In vitro hemocompatibility testing of biomaterials according to the ISO 10993-4. Biomol Eng. 2002;19(2):91-6.

107. Weber M, Steinle H, Golombek S, Hann L, Schlensak C, Wendel HP, Avci-Adali M. Blood-contacting biomaterials: in vitro evaluation of the hemocompatibility, Front Bioeng. Biotechnol. 2018;6:99-99.

108. van der Meijden PEJ, Heemskerk JWM. Platelet biology and functions: new concepts and clinical perspectives. Nat Rev Cardiol. 2019;16(3):166-79.

109. Marx Steven O, Totary-Jain H, Marks Andrew R. Vascular smooth muscle cell proliferation in restenosis. Circulation: Cardiovasc Interv. 2011;4(1):104-11.

110. Meyers SR, Hamilton PT, Walsh EB, Kenan DJ, Grinstaff MW. Endothelialization of titanium surfaces. Adv Mater. 2007;19(18):2492-8.

111. Byrne RA, Serruys PW, Baumbach A, Escaned J, Fajadet J, James S, Joner M, Oktay S, Jüni P, Kastrati A, Sianos G, Stefanini GG, Wijns W, Windecker S. Report of a European Society of Cardiology-European Association of Percutaneous Cardiovascular Interventions task force on the evaluation of coronary stents in Europe: executive summary. Eur Heart J. 2015;36(38):2608-20.

112. Gailani D, Renne T. Intrinsic pathway of coagulation and arterial thrombosis. Arterioscler Thromb Vasc Biol. 2007;27(12):2507-13.

113. Ankrum J. Cell therapies can bring insult to injury. Sci Transl Med. 2020;12(532):eabb0792.

114. Mackman N, Bergmeier W, Stouffer GA, Weitz JI. Therapeutic strategies for thrombosis: new targets and approaches. Nat Rev Drug Discov. 2020;19(5):333-52.

115. Soike T, Streff AK, Guan C, Ortega R, Tantawy M, Pino C, Shastri VP. Engineering a material surface for drug delivery and imaging using layer-by-layer assembly of functionalized nanoparticles. Adv Mater. 2010;22(12):1392-7.

116. Żeliszewska P, Sadowska M, Morga M, Adamczyk Z. Mechanism of fibrinogen /microparticle complex deposition on solid substrates: role of $\mathrm{pH}$. Colloids Surf B: Biointerfaces. 2019;184:110424

117. Castellanos MI, Mas-Moruno C, Grau A, Serra-Picamal X, Trepat X, Albericio F, Joner M, Gil FJ, Ginebra MP, Manero JM, Pegueroles M. Functionalization of CoCr surfaces with cell adhesive peptides to promote HUVECs adhesion and proliferation. Appl Surf Sci. 2017;393:82-92.

118. Windecker S, Mayer I, De Pasquale G, Maier W, Dirsch O, De Groot P, Wu Y-P, Noll G, Leskosek B, Meier B, Hess Otto M. Stent coating with titanium-nitride-oxide for reduction of neointimal hyperplasia. Circulation. 2001;104(8):928-33. 
119. Hasebe T, Ishimaru T, Kamijo A, Yoshimoto Y, Yoshimura T, Yohena S, Kodama H, Hotta A, Takahashi K, Suzuki T. Effects of surface roughness on anti-thrombogenicity of diamond-like carbon films. Diam Relat Mater. 2007;16(4):1343-8.

120. Linneweber J, Dohmen PM, Kertzscher U, Affeld K, Nose Y, Konertz W. The effect of surface roughness on activation of the coagulation system and platelet adhesion in rotary blood pumps. Artif Organs. 2007;31(5):345-51.

121. Schieber R, Lasserre F, Hans M, Fernández-Yagüe M, DíazRicart M, Escolar G, Ginebra M-P, Mücklich F, Pegueroles M. Direct laser interference patterning of $\mathrm{CoCr}$ alloy surfaces to control endothelial cell and platelet response for cardiovascular applications. Adv Healthcare Mater. 2017;6(19):1700327.

122. Choudhary S, Haberstroh KM, Webster TJ. Enhanced functions of vascular cells on nanostructured Ti for improved stent applications. Tissue Eng. 2007;13(7):1421-30.

123. Shih C-C, Shih C-M, Su Y-Y, Su LHJ, Chang M-S, Lin S-J. Effect of surface oxide properties on corrosion resistance of 316L stainless steel for biomedical applications. Corros Sci. 2004;46(2):427-41.

124. Milleret V, Ziogas A, Buzzi S, Heuberger R, Zucker A, Ehrbar M. Effect of oxide layer modification of $\mathrm{CoCr}$ stent alloys on blood activation and endothelial behavior. J Biomed Mater Res B Appl Biomater. 2015;103(3):629-40.

125. Sharma CP. Blood-compatible materials: a perspective. J Biomater Appl. 2001;15(4):359-81.

126. Sousa JE, Serruys Patrick W, Costa Marco A. New frontiers in cardiology. Circulation. 2003;107(17):2274-9.

127. Ren L, Xu L, Feng J, Zhang Y, Yang K. In vitro study of role of trace amount of $\mathrm{Cu}$ release from $\mathrm{Cu}$-bearing stainless steel targeting for reduction of in-stent restenosis. J Mater Sci - Mater Med. 2012;23(5):1235-45.

128. Ren X, Feng Y, Guo J, Wang H, Li Q, Yang J, Hao X, Lv J, Ma $\mathrm{N}, \mathrm{Li}$ W. Surface modification and endothelialization of biomaterials as potential scaffolds for vascular tissue engineering applications. Chem Soc Rev. 2015;44(15):5680-742.

129. Wu G, Li P, Feng H, Zhang X, Chu PK. Engineering and functionalization of biomaterials via surface modification. Journal of Materials Chemistry B. 2015;3(10):2024-42.

130. Weng Y, Chen J, Tu Q, Li Q, Maitz MF, Huang N. Biomimetic modification of metallic cardiovascular biomaterials: from function mimicking to endothelialization in vivo. Interface Focus. 2012;2(3):356-65.

131. Xie D, Wan G, Maitz MF, Sun H, Huang N. Deformation and corrosion behaviors of Ti-O film deposited $316 \mathrm{~L}$ stainless steel by plasma immersion ion implantation and deposition. Surf Coat Technol. 2013;214:117-23.

132. Zhu J-Z, Xiong X-W, Du R, Jing Y-J, Ying Y, Fan X-M, Zhu T-Q, Zhang R-Y. Hemocompatibility of drug-eluting coronary stents coated with sulfonated poly (styrene-block-isobutyleneblock-styrene). Biomaterials. 2012;33(33):8204-12.

133. Hoshi RA, Van Lith R, Jen MC, Allen JB, Lapidos KA, Ameer $\mathrm{G}$. The blood and vascular cell compatibility of heparin-modified ePTFE vascular grafts. Biomaterials. 2013;34(1):30-41.

134. Huang N, Yang P, Leng YX, Chen JY, Sun H, Wang J, Wang GJ, Ding PD, Xi TF, Leng Y. Hemocompatibility of titanium oxide films. Biomaterials. 2003;24(13):2177-87.

135. Huang N, Leng YX, Yang P, Chen JY, Sun H, Wang J, Wan GJ, Zhao AS, Ding PD. Surface modification of coronary artery stent by $\mathrm{Ti}-\mathrm{O} / \mathrm{Ti}-\mathrm{N}$ complex film coating prepared with plasma immersion ion implantation and deposition. Nucl Instrum Methods Phys Res, Sect B. 2006;242(1):18-21.

136. Martinez AW, Chaikof EL. Microfabrication and nanotechnology in stent design. WIREs Nanomed Nanobiotechnol. 2011;3(3):256-68.
137. Navarro L, Luna J, Rintoul I. Surface conditioning of cardiovascular 316L stainless steel stents: a review. Surf Rev Lett. 2016;24(01):1730002.

138. Bekmurzayeva A, Duncanson WJ, Azevedo HS, Kanayeva D. Surface modification of stainless steel for biomedical applications: revisiting a century-old material. Mater Sci Eng, C. 2018;93:1073-89.

139. Zhu S, Huang N, Xu L, Zhang Y, Liu H, Lei Y, Sun H, Yao Y. Biocompatibility of $\mathrm{Fe}-\mathrm{O}$ films synthesized by plasma immersion ion implantation and deposition. Surf Coat Technol. 2009;203(10):1523-9.

140. Zhou WR, Zheng YF. 8 - Characterization of modified magnesium and magnesium alloys for biomedical applications. In: Narayanan TSNS, Park I-S, Lee M-H, editors. Surface modification of magnesium and its alloys for biomedical applications. Oxford: Woodhead Publishing; 2015. p. 263-82.

141. Reejhsinghani R, Lotfi AS. Prevention of stent thrombosis: challenges and solutions. Vasc Health Risk Manag. 2015;11:93-106.

142. Puranik AS, Dawson ER, Peppas NA. Recent advances in drug eluting stents. Int J Pharm. 2013;441(1):665-79.

143. Zhang K, Liu T, Li J-A, Chen J-Y, Wang J, Huang N. Surface modification of implanted cardiovascular metal stents: from antithrombosis and antirestenosis to endothelialization. J Biomed Mater Res, Part A. 2014;102(2):588-609.

144. O'Brien B, Carroll W. The evolution of cardiovascular stent materials and surfaces in response to clinical drivers: a review. Acta Biomater. 2009;5(4):945-58.

145. O'Brien B, Zafar H, Ibrahim A, Zafar J, Sharif F. Coronary stent materials and coatings: a technology and performance update. Ann Biomed Eng. 2016;44(2):523-35.

146. Meadows TA, Bhatt DL. Clinical aspects of platelet inhibitors and thrombus formation. Circ Res. 2007;100(9):1261-75.

147. Kolandaivelu K, Swaminathan R, Gibson WJ, Kolachalama VB, Nguyen-Ehrenreich KL, Giddings VL, Coleman L, Wong GK, Edelman ER. Stent thrombogenicity early in high-risk interventional settings is driven by stent design and deployment and protected by polymer-drug coatings. Circulation. 2011;123(13):1400-9.

148. Liu J, Li M, Lu H, Qiao W, Xi D, Luo T, Xiong H, Guo Z. Effects of probucol on restenosis after percutaneous coronary intervention: a systematic review and meta-analysis. PLoS ONE. 2015;10(4):e0124021-e0124021.

149. Okada T, Yamamoto H, Okimoto T, Otsuka M, Ishibashi K, Dohi Y, Fujii T, Tadehara F, Kurisu S, Hayashi Y, Kihara IY. Coronary Atherosclerosis Reduction Project, Beneficial effects of valsartan on target lesion revascularization after percutaneous coronary interventions with bare-metal stents. Circ J. 2011;75(7):1641-8

150. Trabattoni D, Bartorelli AL. Late occlusive in-stent restenosis of a bare-metal stent presenting with ST-elevation anterior MI: is restenosis better than a late stent thrombosis? Int J Cardiol. 2009;135(2):e65-7.

151. Chen M, Osaki S, Zamora PO. Biological response of stainless steel surface modified by N2O/O2 glow discharge plasma. Appl Surf Sci. 2009;255(16):7257-62.

152. Wiviott SD, Braunwald E, McCabe CH, Horvath I, Keltai M, Herrman JP, Van de Werf F, Downey WE, Scirica BM, Murphy SA, Antman EM. Intensive oral antiplatelet therapy for reduction of ischaemic events including stent thrombosis in patients with acute coronary syndromes treated with percutaneous coronary intervention and stenting in the TRITON-TIMI 38 trial: a subanalysis of a randomised trial. Lancet. 2008;371(9621):1353-63.

153. Hunter TB, Taljanovic MS. Glossary of medical devices and procedures: abbreviations, acronyms, and definitions. Radiographics. 2003;23(1):195-213. 
154. Curry TS, Dowdey JE, Murry RC, Cameron J. Christensen's Introduction to the physics of diagnostic radiology. Am J Phys. 1986;54(4):383-383.

155. Shrivastava S, A.S.M. International. Medical device materials: proceedings from the Materials \& Processes for Medical Devices Conference 2003, 8-10 September 2003, Anaheim. ASM International, Materials Park, 2004.

156. Edelman ER, Seifert P, Groothuis A, Morss A, Bornstein D, Rogers C. Gold-coated NIR stents in porcine coronary arteries. Circulation. 2001;103(3):429-34.

157. Kastrati A, Schomig A, Dirschinger J, Mehilli J, von Welser N, Pache J, Schuhlen H, Schilling T, Schmitt C, Neumann FJ. Increased risk of restenosis after placement of gold-coated stents: results of a randomized trial comparing gold-coated with uncoated steel stents in patients with coronary artery disease. Circulation. 2000;101(21):2478-83.

158. Kereiakes DJ, Cox DA, Hermiller JB, Midei MG, Bachinsky WB, Nukta ED, Leon MB, Fink S, Marin L, Lansky AJ. Usefulness of a cobalt chromium coronary stent alloy. Am J Cardiol. 2003;92(4):463-6.

159. Hehrlein C, Schorch B, Kress N, Arab A, von zur Mühlen C, Bode C, Epting T, Haberstroh J, Mey L, Schwarzbach H, Kinscherf R, Stachniss V, Schiestel S, Kovacs A, Fischer H, Nennig E. Zn-alloy provides a novel platform for mechanically stable bioresorbable vascular stents. PLoS One. 2019;14(1):e0209111.

160. Ormiston JA, Webster MWI, Armstrong G. First-in-human implantation of a fully bioabsorbable drug-eluting stent: the BVS poly-L-lactic acid everolimus-eluting coronary stent. Catheter Cardiovasc Interv. 2007;69(1):128-31.

161. Nayak SM. MRI: basic principles and applications. Radiology. 1996;200(1):142-142.

162. Rutledge JM, Vick Iii GW, Mullins CE, Grifka RG. Safety of magnetic resonance imaging immediately following Palmaz stent implant: a report of three cases. Catheter Cardiovasc Interv. 2001;53(4):519-23.

163. Syed MA, Carlson K, Murphy M, Ingkanisorn WP, Rhoads KL, Arai AE. Long-term safety of cardiac magnetic resonance imaging performed in the first few days after bare-metal stent implantation. J Magn Reson Imaging. 2006;24(5):1056-61.

164. Schenck JF. The role of magnetic susceptibility in magnetic resonance imaging: MRI magnetic compatibility of the first and second kinds. Med Phys. 1996;23(6):815-50.

165. Cano ME, Cordova-Fraga T, Sosa M, Bernal-Alvarado J, Baffa O. Understanding the magnetic susceptibility measurements by using an analytical scale. Eur J Phys. 2008;29(2):345-54.

166. Abizaid A, Carrié D, Frey N, Lutz M, Weber-Albers J, Dudek D, Chevalier B, Weng S-C, Costa RA, Anderson J, Stone GW. 6-month clinical and angiographic outcomes of a novel radiopaque sirolimus-eluting bioresorbable vascular scaffold: the FANTOM II Study. JACC: Cardiovasc Interv. 2017;10(18):1832-8.
167. Pugliese F, Cademartiri F, van Mieghem C, Meijboom WB, Malagutti P, Mollet NRA, Martinoli C, de Feyter PJ, Krestin GP. Multidetector CT for visualization of coronary stents. Radiographics. 2006;26(3):887-904.

168. Waksman R, Pakala R, Kuchulakanti PK, Baffour R, Hellinga D, Seabron R, Tio FO, Wittchow E, Hartwig S, Harder C, Rohde R, Heublein B, Andreae A, Waldmann K-H, Haverich A. Safety and efficacy of bioabsorbable magnesium alloy stents in porcine coronary arteries. Catheter Cardiovasc Interv. 2006;68(4):607-17.

169. Hug J, Nagel E, Bornstedt A, Schnackenburg B, Oswald H, Fleck E. Coronary arterial stents: safety and artifacts during MR imaging. Radiology. 2000;216(3):781-7.

170. Li XM, Li HZ, Wang SP, Huang HM, Huang HH, Ai HJ, Xu J. MRI-compatible Nb-60Ta-2Zr alloy used for vascular stents: haemocompatibility and its correlation with protein adsorption, Materials science \& engineering. C, Materials for biological applications. 2014;42:385-95.

171. Guo Y, Duan W, Ma C, Jiang C, Xie Y, Hao H, Wang R, Li L. Biocompatibility and magnetic resonance imaging characteristics of carbon nanotube yarn neural electrodes in a rat model. Biomed Eng Online. 2015;14(1):118.

172. Li HF, Zhou FY, Li L, Zheng YF. Design and development of novel MRI compatible zirconium- ruthenium alloys with ultralow magnetic susceptibility. Sci Rep. 2016;6:24414.

173. Guo S, Zhang J, Shang Y, Zhang J, Meng Q, Cheng X, Zhao X. A novel metastable $\beta$-type $\mathrm{Zr}-12 \mathrm{Nb}-4 \mathrm{Sn}$ alloy with low Young's modulus and low magnetic susceptibility. J Alloy Compd. 2018;745:234-9.

174. Lopič N, Jelen A, Vrtnik S, Jagličić Z, Wencka M, Starc R, Blinc A, Dolinšek J. Quantitative determination of magnetic force on a coronary stent in MRI. J Magn Reson Imaging. 2013;37(2):391-7.

175. Arbustini E, Favalli V, Narula J. Functionally incomplete reendothelialization of stents and neoatherosclerosis. JACC: Cardiovasc Interv. 2017;10(23):2388.

176. Gareri C, De Rosa S, Indolfi C. MicroRNAs for restenosis and thrombosis after vascular injury. Circ Res. 2016;118(7):1170-84.

177. Hoare D, Bussooa A, Neale S, Mirzai N, Mercer J. The future of cardiovascular stents: bioresorbable and integrated biosensor technology. Advanced Science. 2019;6(20):1900856.

178. Maor E, Eleid Mackram F, Gulati R, Lerman A, Sandhu Gurpreet $\mathrm{S}$. Current and future use of robotic devices to perform percutaneous coronary interventions: a review. J Am Heart Assoc. 2017;6(7):e006239.

179. Fagogenis G, Mencattelli M, Machaidze Z, Rosa B, Price K, Wu F, Weixler V, Saeed M, Mayer JE, Dupont PE. Autonomous robotic intracardiac catheter navigation using haptic vision. Sci Robot. 2019;4(29):eaaw1977.

180. Grist TM. The next chapter in MRI: back to the future? Radiology. 2019;293(2):394-5.

\section{Authors and Affiliations}

\section{Jithin Vishnu ${ }^{1}$ - Geetha Manivasagam ${ }^{1}(1) \cdot$ Diego Mantovani $^{2} \cdot$ Anjaneyulu Udduttula ${ }^{3,4} \cdot$ Melanie J. Coathup $^{5}$. Ketul C. Popat ${ }^{6} \cdot$ Pei-Gen Ren $^{3} \cdot$ K. G. Prashanth ${ }^{1,7}$}

1 Centre for Biomaterials, Cellular and Molecular Theranostics, CBCMT, Vellore Institute of Technology, Vellore 632014, India

2 Lab. for Biomaterials and Bioengineering, Department of Mining, Metallurgical and Materials Engineering \& CHU de Quebec Research Centre, Laval University, Quebec City, QC, Canada

3 Center for Energy Metabolism and Reproduction, Shenzhen Institute of Advanced Technology, Chinese Academy of Sciences, Shenzhen 518055, Guangdong, China 
4 School of Engineering, Newcastle University, Newcastle upon Tyne NE1 7RU, UK

5 Biionix Cluster and College of Medicine, University of Central Florida, 6900 Lake Nona Blvd, Orlando, FL 32827, USA
6 Department of Mechanical Engineering, Colorado State University, Fort Collins, CO 80523, USA

7 Department of Mechanical and Industrial Engineering, Tallinn University of Technology, Ehitajate tee 5, 19086 Tallinn, Estonia 